\title{
Modeling of high temperature thermal energy storage in rock beds - Experimental comparison and parametric study
}

Marongiu, Fabrizio; Soprani, Stefano; Engelbrecht, Kurt

Published in:

Applied Thermal Engineering

Link to article, DOI:

10.1016/j.applthermaleng.2019.114355

Publication date:

2019

Document Version

Peer reviewed version

Link back to DTU Orbit

Citation (APA):

Marongiu, F., Soprani, S., \& Engelbrecht, K. (2019). Modeling of high temperature thermal energy storage in rock beds - Experimental comparison and parametric study. Applied Thermal Engineering, 163, [114355]. https://doi.org/10.1016/j.applthermaleng.2019.114355

\section{General rights}

Copyright and moral rights for the publications made accessible in the public portal are retained by the authors and/or other copyright owners and it is a condition of accessing publications that users recognise and abide by the legal requirements associated with these rights.

- Users may download and print one copy of any publication from the public portal for the purpose of private study or research.

- You may not further distribute the material or use it for any profit-making activity or commercial gain

- You may freely distribute the URL identifying the publication in the public portal 


\title{
Modeling of High Temperature Thermal Energy Storage in Rock Beds - Experimental comparison and parametric study
}

\author{
Fabrizio Marongiu ${ }^{\mathrm{a}, \mathrm{b}}$, Stefano Soprani ${ }^{\mathrm{a}}$, Kurt Engelbrecht $\mathrm{a}^{\mathrm{*}}$ \\ a Department of Energy Conversion and Storage, Technical University of Denmark, Frederiksborgvej 399, \\ 4000 Roskilde, Denmark. \\ ${ }^{b}$ Polytechnic University of Milano, Piazza Leonardo da Vinci, 32, 20133 Milano, Italy.
}

\begin{abstract}
The increasing penetration of renewables in energy systems requires the integration of energy storage units into electrical grids as a crucial aspect. Nevertheless, current ES technologies show, as a common issue, an excessive capital cost, which prevents them from being implemented on a large scale. The combination of high temperature thermal energy storage and bottom steam cycles has recently become an object of interest as a potential cost-effective alternative to traditional ES. In this study, a twodimensional model of an existing high temperature thermal energy storage rock bed unit with $450 \mathrm{kWh}_{\text {th }}$ of thermal capacity is implemented. A description of the geometry, equations and boundary conditions is provided, as well as a comparison of the model results with the experimental data logged from the reference testing unit. A brief discussion about the solution method and the relative error on the final results is also presented. A study regarding the charge phase was performed, with the main focus on the modification of some parameters of interest such as rock size, air flow rate, rock type and insulation material. Results are presented in terms of two-dimensional temperature profiles, charge efficiencies and heat losses, highlighting the differences between the scenarios considered. Thermal charge efficiency was found in the range $69-96 \%$ for the considered simulations, and different improvement aspects are suggested for future studies.
\end{abstract}

\section{Introduction}

Energy storage (ES) has become of interest recently in response to the evolution of the energy market. The intermittency and unpredictability of renewable energy sources (RES), like wind and solar power, and the time-dependence of electricity demand are two aspects that contribute significantly to the rise of challenges both on the grid and market sides [1], [2]. As a matter of fact, in countries with a large fraction of electricity supplied by renewables, such as Denmark, large and sudden fluctuations of energy prices are common due to the imbalance between energy production and demand [3]. In this scenario, ES can play an important role in creating a more flexible and reliable electricity system with lower average electricity prices. It can be used, for instance, for grid balancing purposes, e.g. decreasing the imbalance between electricity demand and production or mitigating grid congestion, and as a supply capacity reserve, which is of paramount importance during peak-demand periods or as a response to grid failures [4]. As a major outcome, ES provides stability to spot market prices. As a downside, however, the main issue of a great number of the current ES systems is the high capital cost, which entails the need for incentive schemes [5]. 
ES technologies of main interest nowadays are [6]: solid state batteries [7], flow batteries [8], compressed air energy storage (CAES) [9], flywheels [10], pumped hydro [11], electrolysis [12] and thermal energy storage (TES) [13]. TES features three different means of storing heat [14]: thermo-chemical [15], where heat is stored by means of a chemical reaction (e.g. ammonia dissociation), latent heat [16], meaning heat storage in the phase change of a material (e.g. salt hydrates), and sensible heat [17], in which a heat storage medium increases in temperature (e.g. water, gravel, rocks). Applications of TES include (i) CSP plants, with the goal of decoupling the solar availability from the power block activity [18], (ii) waste heat recovery [19], (iii) heating and cooling systems [20] and (iv) power-to-power operation. Concerning the last item, it can be implemented in a high-temperature TES (HTTES) system that converts and stores lowcost electricity from the grid as high-temperature heat, around $600^{\circ} \mathrm{C}$, and transforms it back to electricity by means of a bottom steam cycle when prices are higher.

\subsection{HTTES in Rock beds}

Rock beds represent a promising sensible heat HTTES system due to the abundancy of the storage material and its consequent relatively low cost, along with a wide temperature range of applicability. Their advantages also include: (i) heat transfer by contact between working fluid and storage material [21], which results in low temperature differences between the two phases, (ii) minimal degradation and thermal instability issues, (iii) no safety-related concerns [22], (iv) absence of chemicals that can represent a potential environmental issue, (v) low response time [23] and (vi) economic advantages with scaling [24]. The main drawback of this technology is the low overall efficiency, in comparison to many ES technologies, and the low energy density, which results in the need for massive structures, for which larger fans are required and therefore operational cost may grow accordingly [25]. In addition to this, thermal ratcheting, i.e. the different thermal expansion between rocks and container walls, represents a technological challenge in terms of mechanical effects on the surrounding structure over a large number of thermal cycles; for this reason an adequate design of the container is an aspect of considerable importance [26].

Models regarding rock-bed storage systems date back to 1929, when Schumann [27] proposed an analytical solution for the problem of heat exchange between a flowing fluid and a porous medium, in response to a temperature step variation of the first one. Later literature focused on the description of transient behavior and on the expansion of the operating conditions beyond those stated in the Schumann's model. Shitzer and Levy [25] simplified Schumann's solution and adapted it to the case of variable temperature of the inlet air flow. In their work, the bed and fluid temperatures were calculated applying Duhamel's theorem, and the solution was found in terms of infinite double series based on Schumann's results. Experimental validation of the numerical solution was also provided. Coutier and Farber [28] gave a numerical solution to the heat transfer problem inside a rock bed, also accounting for secondary phenomena such as thermal losses and conduction effects. Two applications of the model were studied. The first one is a method for the calculation of the volumetric convective heat transfer coefficient comparing results from a numerical model and experimental tests. The second one is a design method of the rock-bed storage for solar applications, focused on the determination of optimal values for parameters such as air velocity, particle diameter and various geometrical aspects. Beasley and Clark [29] provided a solution to a time-dependent model in two spatial dimensions, considering the influence of thermal dispersion both in axial and radial directions. Both charge and recovery phases were included in the study. Focus was also put on the analysis of the influence of some aspects like porosity, radial velocity variations, wall heat capacity and thermal losses. Different modeling approaches for packed beds, both 
for sensible heat storage and phase change materials, were analyzed by Ismail and Stuginsky [30]. In particular, continuous solid phase models, Schumann's model, single phase models and thermal diffusion models were considered. The comparison was performed on the basis of computational time and in relation to the influence of some parameters of interest, such as particle size, porosity, solid material and flow rate. More recently, Andreozzi et al. [31] investigated the impact of radiation heat transfer, inlet mass flow rate, porosity and heat losses through lateral walls on the performance of the packed bed, with charging temperatures up to $1200^{\circ} \mathrm{C}$, by means of the software ANSYS FLUENT.

Various studies analyzed second law efficiencies and the main sources of irreversibilities. In particular, Krane [32] focused on the optimal design of a sensible heat TES system through the minimization of entropy generation, considering the TES unit as a lumped storage element. The main results of his work were that (i) both charge and recovery phase must be considered in the optimization of such a system and that (ii) a typical optimized unit loses approximately $70 \%$ to $90 \%$ of the entering reversible work, therefore entailing a low thermodynamic efficiency. In a later publication, Taylor et al. [33] expanded Krane's analysis by including entropy generation from transient heat conduction within the storage element. The main difference from [32] is that the TES unit was considered as a distributed storage element, not a lumped one. More recently, Navarrete-Gonzalez et al. [34] analyzed energy and exergy balances of a rock bed TES system by means of a numerical model. Experimental validation for the model solution was also presented.

Focus in the literature was also put on the evaluation of friction factors and pressure drops in packed beds, due to the consequences that this aspect entails in fan dimensioning. Ergun [35] presented a correlation for the calculation of pressure drop applicable to all types of flow. Its dependence on flow rate, fluid properties, porosity, particle size, orientation, shape and surface roughness of the solid was analyzed. In a later publication, Allen et al. [36] showed how experimental data differ from the results of Ergun's equation when considering air passing through different types of porous media. The influence of particle shape, arrangement and surface roughness upon the pressure drop was investigated as well. More recently, Zavattoni et al. [37] presented a 3D CFD model with the goal of investigating the effects of the axial porosity distribution of the packed material on the heat transfer. Different scenarios were analyzed: constant porosity value, linear and quadratic porosity variations. Results confirmed the relevance of the aspect under investigation in terms of convection, thermal radiation, and axial conductivity inside the porous medium. Allen et al. [38] formulated empirical correlations depending on rock type and packing method. In the same paper, a study focused on defining the cost-optimum bed dimensions and particle size for a vertical setup was presented. In a later publication, Allen et al. [39], empirical correlations based on the particle volume-equivalent sphere diameter were described, in order to estimate the friction factor for two different packing directions. Correlations based on a simplified Nusselt number for the calculation of heat transfer coefficients in packed beds were also presented.

Recently, repetitive consecutive cycles of charge and discharge phases were also modeled. The first study concerning this aspect was performed by Singh et al. [40], albeit no experimental validation is performed for the presented model. Scenarios with different storage materials were analyzed, namely glass and steel were both modelled using water as the fluid phase. The main goal was to investigate the dependence of temperature profiles and storage effectiveness on packed bed length, particle size and solid phase characteristics. Zavattoni et al. [41] investigated cyclic behavior of rock bed TES systems for industrialscale CSP plants, providing also an experimental validation of the model. The main outcomes of this study regarded evolution of the thermocline thickness and efficiency change under cyclic conditions. Agalit et 
al. [42] proposed a one-dimensional two-phase heat transfer model for the investigation of high temperature solar packed bed TES over repetitive cycles in hybrid solar tower power plants. In this work, an experimental validation is also presented. The cyclic performance of the bed is described with a particular focus on reducing the computational time with respect to already-existing models. In a later publication, Geissbühler et al. [43] built a model for the simulation of a high-temperature combined sensible/latent thermal energy storage. In their work, experimental validation is performed and the analysis of industrial scale systems over several charge-discharge cycles is presented. Results showed that material costs and exergy efficiency meet the goal set by the U.S. Department of Energy's SunShot Initiative. Hänchen et al. [44] presented a parametric study based on an experimentally validated numerical heat transfer model of a vertical cylindrical packed bed, accounting for heat losses through the walls. The influence of length of the rock bed, fluid flow rate, particle diameter and different solid materials was analyzed. Results focused mainly on daily cyclic operation, overall thermal efficiency and capacity ratio. Zanganeh et al. [45] proposed a quasi-one-dimensional two-phase heat transfer model for a truncated conical shaped rock bed, considering temperature-dependent thermophysical properties of both fluid and solid phases, heat losses through the walls and axial conduction through the packed bed. A parametric study over repetitive charge-discharge cycles was performed, focusing in particular on the effects on the storage efficiency of different initial charging state of the storage, cone angle of the container, insulation thickness on the container walls, rock diameter and tank diameter-to-height ratio. For all the considered simulations, efficiency was higher than $95 \%$.

\subsection{Goal of the present work}

The goal of the present work is to build a numerical two-dimensional heat transfer model for the parametric study of a horizontal flow rock bed during the charge phase. Temperature-dependent thermophysical properties are considered both for the fluid and solid phases. Time-dependent experimental inlet temperature data is used for the inlet air in the model. A description and experimental validation of the model is provided. A parametric study is performed in order to investigate the effect on the storage performance of different inlet air flow rates, rock sizes, rock types and external insulation layers. Results can serve as guidelines for design and operation of horizontal rock bed HTTES units on an industrial scale and can pave the way for future investigation of repetitive charge-discharge cycles on storage systems with the same flow orientation.

\section{Model description}

\subsection{Geometry and materials}

The two-dimensional model geometry consists of a rock-filled steel container with inlet and outlet pipes for air flow (Figure 1b), reproducing the geometry of the existing experimental setup (Figure 1a). Container and pipes are made of stainless steel AISI 316, with thermal insulation as shown in Figure 1a. A further description of the domains is provided in Table 1. Two air inlets and outlets are designed to provide flexibility to the air flow distribution in the rock bed, and two vertical pipes convey the air to the chimney during the charge (right pipe) and discharge phases (left pipe). Empty rooms, called pre-rooms later in the text, are interposed between the inlet pipes and the rock bed, in order to let the air flow distribute more evenly when entering the porous media. This structure is present on both sides of the setup in order to cover this aspect also during the discharge phase, when the air flow is reversed. A description of the system design is shown in Figure 1a. The out-of-plane dimension (thickness) of the experimental setup is $1 \mathrm{~m}$. 

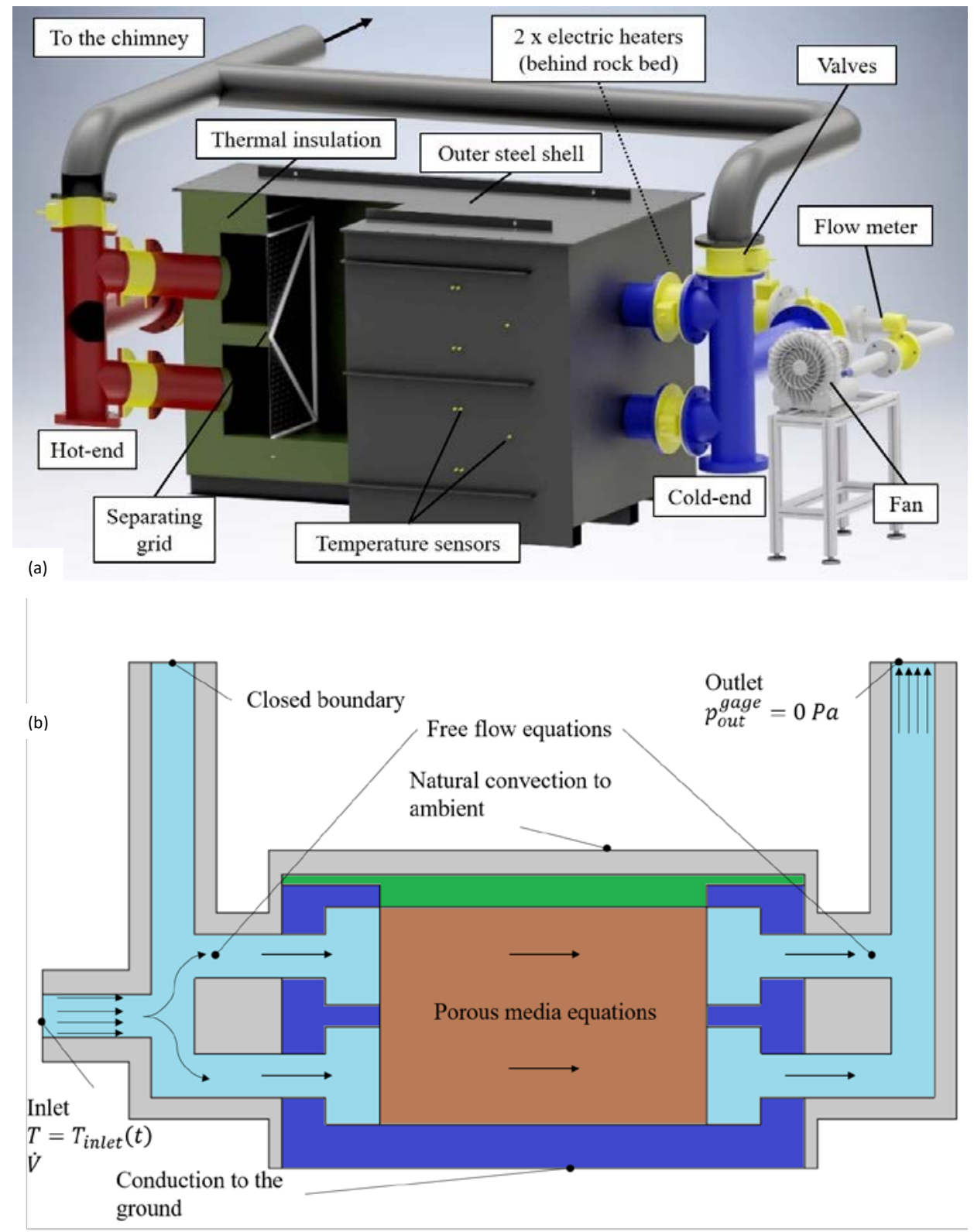

Figure 1. A rendering of the system design (a) with external equipment such as the fan included and a schematic of the 2D model (b). 
Table 1. Description of the modelling domains illustrated in Figure 1(a).

\begin{tabular}{cccc} 
Color & Component & Material & Dimensions \\
\hline Brown & Rock bed & Swedish diabase and air & $1 \times 1.5 \mathrm{~m}$ \\
\hline Light blue & $\begin{array}{c}\text { Inlet/outlet pipes and } \\
\text { pre-rooms }\end{array}$ & Air & $\begin{array}{c}\text { Pipe diameter } 0.2 \mathrm{~m} \\
\text { Pre-rooms height } 0.4 \mathrm{~m}\end{array}$ \\
\hline Blue & Hard insulation & Skamol & $\begin{array}{c}\text { Thickness (thinner parts) } 0.1 \mathrm{~m} \\
\text { Thickness (elsewhere) } 0.2 \mathrm{~m}\end{array}$ \\
\hline Green & Soft insulation & Superwool HT blanket & $\begin{array}{c}\text { Thickness (above rocks) } 0.15 \mathrm{~m} \\
\text { Thickness (elsewhere) } 0.05 \mathrm{~m}\end{array}$ \\
\hline Grey & Soft insulation & Rockwool SeaRox SL & $\begin{array}{c}\text { Thickness (thinner parts) } 0.05 \mathrm{~m} \\
\text { Thickness (elsewhere) } 0.1 \mathrm{~m}\end{array}$
\end{tabular}

Table 2. Structural material properties used in the model, from producer's technical sheets.

\begin{tabular}{cccc} 
Material & $\begin{array}{c}\text { Density } \\
\left(\mathbf{k g} / \mathbf{m}^{\mathbf{3}}\right)\end{array}$ & $\begin{array}{c}\text { Specific heat capacity } \\
(\mathbf{J} / \mathbf{( k g - K )})\end{array}$ & $\begin{array}{c}\text { Thermal conductivity } \\
(\mathbf{W} /(\mathbf{m}-\mathbf{K}))\end{array}$ \\
\hline $\begin{array}{c}\text { Skamol } \\
\begin{array}{c}\text { Superwool HT } \\
\text { blanket }\end{array}\end{array}$ & 700 & 800 & 0.155 \\
\hline $\begin{array}{c}\text { Rockwool SeaRox } \\
\text { SL 660 }\end{array}$ & 128 & 1050 & 0.08 \\
\hline $\begin{array}{c}\text { Stainless steel } \\
\text { AlSI 316 }\end{array}$ & 150 & 840 & 0.073 \\
\hline
\end{tabular}

Constant thermophysical properties were assumed for the insulation and container materials (Table 2). Temperature-dependent properties, instead, were used for air [46] and the rock materials. Two types of rocks are considered in the present analysis, Swedish diabase and magnetite, as these were identified as two of the most promising rock types for HTTES applications [24], [47]. The density, $\rho$, and specific heat capacity, $c$, as a function of temperature for both materials were experimentally measured. The behavior of the volumetric heat capacity $\rho c$ is shown in Figure 2. The curve of magnetite shows a peak approximately at $560^{\circ} \mathrm{C}$ that is related to the ferromagnetic to paramagnetic magnetic phase transformation that occurs at the material's Curie temperature. This phenomenon is reversible. References for thermal conductivity properties of diabase was Birch and Clark [48], and Grosu et al. [49] for raw magnetite. Thermophysical properties at $500^{\circ} \mathrm{C}$ are reported in Table 3.

Table 3. Thermophysical properties of the modelled rocks at $500^{\circ} \mathrm{C}$.

\begin{tabular}{cccc} 
Material & $\begin{array}{c}\text { Density } \\
\left(\mathbf{k g} / \mathbf{m}^{\mathbf{3}}\right)\end{array}$ & $\begin{array}{c}\text { Heat capacity } \\
\left(\mathbf{k J} /\left(\mathbf{m}^{\mathbf{3}}-\mathbf{K}\right)\right)\end{array}$ & $\begin{array}{c}\text { Thermal conductivity } \\
(\mathbf{W} / \mathbf{( m - K ) )}\end{array}$ \\
\hline Swedish diabase & 3007 & 3824.9 & 1.75 \\
\hline Magnetite & 5150 & 5819.5 & 1.9
\end{tabular}




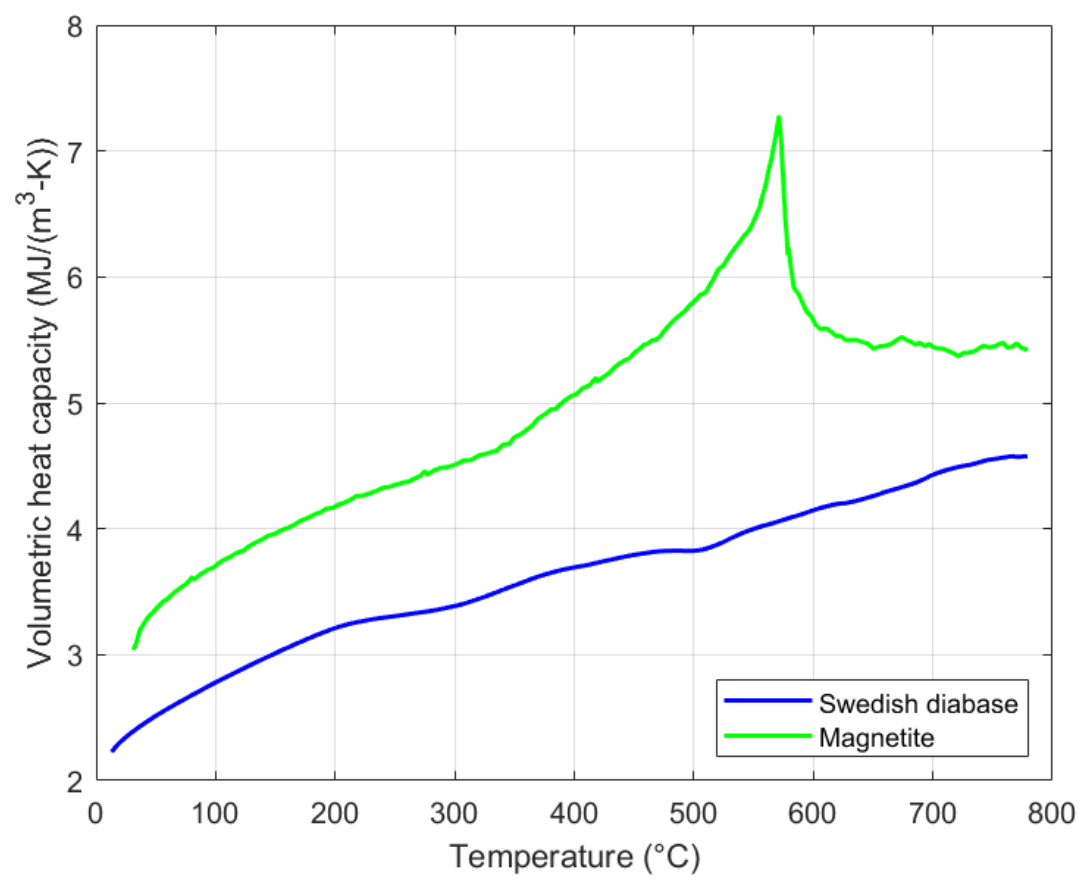

Figure 2. Volumetric heat capacity $(\rho c)$ behavior as a function of temperature for rock materials used in the simulations.

\subsection{Equations}

The modeling activity was performed with the goal of simulating the temperature distribution inside the rock bed during the charge phase in order to assess the overall efficiency of the storage. The governing system of equations results from the coupling of mass, momentum and energy conservation equations in all the domains. More precisely, the model is made up of continuity and Navier-Stokes equations for free flow of air in pipes (light blue domain in Figure 1b), where free flow indicates forced convection through a section in which no porous medium is present, continuity and Brinkman's equation (Eq. 1) for porous media flow (brown domain in Figure 1b), and the energy equations in the fluid (Eq. 3) and solid phases (Eq. 4).

$$
\frac{\rho}{\varepsilon}\left(\frac{\partial \boldsymbol{v}}{\partial t}+(\boldsymbol{v} \cdot \nabla) \frac{\boldsymbol{v}}{\varepsilon}\right)=\nabla \cdot\left[-p \boldsymbol{I}+\frac{\mu}{\varepsilon}\left(\nabla \boldsymbol{v}+(\nabla \boldsymbol{v})^{T}\right)-\frac{2 \mu}{3 \varepsilon}(\nabla \cdot \boldsymbol{v}) \boldsymbol{I}\right]-\left(\frac{\mu}{K}+\beta|\boldsymbol{v}|\right) \boldsymbol{v}+\rho \boldsymbol{g}
$$

Regarding the fluid-dynamics equations, major focus must be put on Brinkman's equation. In fact, it contains the term $\rho g$, which considers the gravity effects on the flow distribution in the setup, namely buoyancy phenomena, for which hot air flow tends to distribute in the upper region of the rock bed. In addition to this, the permeability $K$ is a noteworthy parameter in this equation. It is likely the main source of uncertainty in the model, given the inherent complexity of its estimation. For the present model, it was calculated by means of the Carman-Kozeny equation (Eq. 2), 


$$
K=\frac{\varepsilon^{3}}{180(1-\varepsilon)^{2}} D_{p}^{2}
$$

where $\varepsilon$ is the porosity and $D_{p}$ is the rock size. The energy conservation equations for such a heat regenerator were first reported by Nusselt according to [50]. The conduction term through the porous matrix is included in the solid domain energy equation (Eq. 4) in order to consider the thermal conduction inside the bed. The conduction term is the first term on the right hand side in Eq. 4. In addition to this, local thermal non equilibrium is assumed between air and rocks, hence the convective heat exchange term between the two phases is also present in both the equations.

$$
\begin{aligned}
& \varepsilon\left(\frac{\partial(\rho c)_{f} T_{f}}{\partial t}+\nabla \cdot(\rho c)_{f} \frac{\boldsymbol{v}}{\varepsilon} T_{f}\right)=h_{c o n v} a_{s}\left(T_{s}-T_{f}\right)+Q_{\text {lost }} \\
& (1-\varepsilon)\left(\frac{\partial(\rho c)_{s} T_{s}}{\partial t}\right)=\nabla \cdot\left(k_{e f f} \nabla T_{s}\right)+h_{\text {conv }} a_{s}\left(T_{f}-T_{s}\right)
\end{aligned}
$$

Where $k_{e f f}$ is the effective thermal conductivity of the rock bed, $h_{\text {conv }}$ is the local convection coefficient between air and rocks and $a_{s}$ is the specific surface area. The parameter $k_{e f f}$ was calculated as a weighted arithmetic mean of air and porous medium conductivities, i.e. $k_{e f f}=\varepsilon \cdot k_{f}+(1-\varepsilon) \cdot k_{s}$, in which $f$ represents the fluid and $s$ the solid phase. The reason for this was to consider the different heat transfer mechanisms taking place in the porous medium resulting in axial dispersion, i.e. thermal conduction through solid phase (1), conduction through contact regions of different rocks (2) and through the gas film in proximity of the contact areas of different stones (3), heat transfer between neighboring empty volumes (4) [41]. Heat transfer by radiation was not included in the present analysis. The term of heat losses towards the environment, $Q_{\text {lost }}$, was calculated considering conduction through the ground and convection from the walls to the external ambient, assuming ambient air at $15^{\circ} \mathrm{C}$. Different convection coefficients were calculated based on [51], according to the shape and orientation of the considered wall. Each of these coefficients is a function of the surface temperature of the setup, hence it is dependent on time and location. As regards $h_{c o n v}$, it was calculated from:

$$
h_{\text {conv }}=\frac{N u k_{f}}{D_{p}}
$$

Where $N u$ is the Nusselt number, calculated as stated in Wakao et al. [52].

Equations 1, 3 and 4 can be non-dimensionalized and the most common dimensionless numbers used to characterize regenerator operation are the utilization, $U$, and NTU, which is also called the reduced regenerator length [50]. The utilization is defined as:

$$
U=\frac{\dot{m}_{f} c_{p, f} t_{f}}{m_{r} c_{r}}
$$

where $c_{p, f}$ and $c_{r}$ are the average specific heat capacity of air and of the rocks, respectively, $m_{r}$ is the mass of rocks, $\dot{m}_{f}$ is the mass flow rate of air and $t_{f}$ is the cycle duration. The NTU is defined as:

$$
N T U=\frac{h_{c o n v} a_{s} L}{\dot{m}_{f} c_{p, f}}
$$


Where $L$ is the length of the rock bed.

Assumptions at the basis of this model are: (i) compressible Newtonian fluid, (ii) isotropic porous medium and (iii) rigid pore geometry. Boundary conditions for fluid flow equations are:

- no-slip condition on the fluid-bounding walls;

- zero gage outlet pressure.

Regarding the energy conservation equations, the boundary conditions are:

- inlet temperature is an input, which is the experimental result from fluid temperature logged for a reference experimental test;

- $\quad \boldsymbol{n} \cdot\left(-k \frac{\partial T}{\partial z}\right)=0$ at the outlet, namely an outflow condition, where $\boldsymbol{n}$ is the surface normal vector;

- natural convective heat flux on the outer surface of the domain, from which $q_{\text {ext }}=\alpha\left(T_{\text {ext }}-\right.$ $T$ ), with the convective coefficient $\alpha$ calculated as stated above.

Initial conditions for these equations are: (i) null fluid velocity field; (ii) null relative pressure in the fluid domain; (iii) thermal equilibrium at ambient temperature for both solid and fluid phases.

Other dimensionless groups were used for a more complete description of the operating conditions. First, the flow is characterized by the free flow Reynolds number based on the particle diameter, where $\bar{v}$ is intended as the average fluid flow velocity in the rock bed cross-section area:

$$
R e_{p}=\frac{\bar{v} \rho_{f} D_{p}}{\mu_{f}}
$$

Second, In order to describe the air flow inside the porous medium, mainly to understand the relationship between forced convection, induced by the fan, and natural convection, due to buoyancy forces caused by the thermal gradient inside the rock bed, the Richardson number was also considered:

$$
R i=\frac{G r_{H}}{R e_{L}^{2}}
$$

Where $G r_{H}$ is the Grashof number (Eq. 9) and $R e_{L}$ is the free flow Reynolds number based on the bed length (Eq. 10).

$$
G r_{H}=\frac{\rho_{f}|g| \beta_{f}\left(T_{h}-T_{r e f}\right) H^{3}}{\mu_{f}}
$$


where $g$ is the gravity acceleration, $\beta_{f}$ is the thermal expansion coefficient of air, $T_{h}$ is the hot air temperature, i.e. $600^{\circ} \mathrm{C}, T_{\text {ref }}$ is the reference temperature, i.e. $15^{\circ} \mathrm{C}, \mathrm{H}$ is the height of the bed in the cross-flow direction.

$$
\operatorname{Re}_{L}=\frac{\bar{v} \rho_{f} L}{\mu_{f}}
$$

In addition to this, the Biot number (Eq. 12) was used in order to characterize the temperature gradients inside the individual stones. Assuming spherical particles, for all the cases considered in this paper, Bi was found to be lower than 0.1 , therefore single rocks were treated as bodies at uniform temperature, as seen in [45].

$$
B i=\frac{h_{\text {conv }} R_{p}}{k_{r}}
$$

Where $R_{p}$ is the rock radius. The calculation of all dimensionless numbers but $R i$ was performed using material properties at $600^{\circ} \mathrm{C}$ (the inlet temperature). The Richardson number, instead, was evaluated at the average temperature of $300^{\circ} \mathrm{C}$, in order to account for the temperature gradient inside the rock bed during the charge phase.

\subsection{Solution strategy}

The presented two-dimensional model was numerically solved with the finite element method (FEM) approach by means of the software COMSOL Multiphysics 5.3. Backward differentiation formula was used as the time-stepping method, with a tolerance factor of 0.05 and maximum time-step of $0.1 \mathrm{~s}$. For the mesh, maximum and minimum element sizes were set to $0.281 \mathrm{~m}$ and $0.00126 \mathrm{~m}$. The total number of domain elements was, therefore, 6015 , whereas the number of boundary elements was 678 .

For all the simulations considered in this paper, the average value of the relative error on the overall energy balance is $2.73 \%$, with a maximum of $4.11 \%$. This is due to the solution of the numerical model, mainly the initial timestep, maximum timestep and number of nodes. An investigation regarding the influence of these parameters was performed in order to achieve the best convergence of the model. For the initial and maximum time-step, they were reduced to, respectively, $0.025 \mathrm{~s}$ and $0.0625 \mathrm{~s}$. Results showed a negligible difference in the relative error, despite a longer computational time, when reducing these parameters. A slightly larger improvement $(0.8 \%)$ was noticed when reducing the maximum and minimum element size of the mesh up to, respectively, $0.155 \mathrm{~m}$ and $5.25 \mathrm{E}-04 \mathrm{~m}$. The computational time doubled, hence the above-mentioned values were kept as reference for all the tests.

\section{Experimental comparison}

In order to check the validity of the model, a comparison with experimental data, selected from [47], was performed. A description of the experimental setup is provided in Figure 3 and Table 4, with a more detailed description given in [47]. The test section is filled with Swedish diabase sieved between $16 \mathrm{~mm}$ and $22 \mathrm{~mm}$ openings. The test section is $1 \mathrm{~m}$ by $1 \mathrm{~m}$ in cross section and $1.5 \mathrm{~m}$ in length, giving a total volume of $1.5 \mathrm{~m}^{3}$ and $2495 \mathrm{~kg}$ of rock material. The porosity is estimated as 0.45 . Thermocouple locations 
inside the HTTES unit are shown in Figure 4. As pointed out by the legend, dots represent thermocouples aligned in the middle of the rock bed, whereas triangles stand for thermocouples close to the container's wall, more precisely at a distance of $50 \mathrm{~mm}$ from it, all on the same side. Thermocouples laying on row 1 and row 4 of Figure 4 will be referred to as top and bottom layers of thermocouples. During construction, a $13 \mathrm{~mm}$ thick layer of soft insulation was installed in direct contact with the rocks with the goal of creating a conforming wall, which should reduce edge effects and flow channeling at the rock bed walls. However, no thermocouples were installed directly at the walls or in the corners of the flow cross section to confirm that no flow channeling occurred.

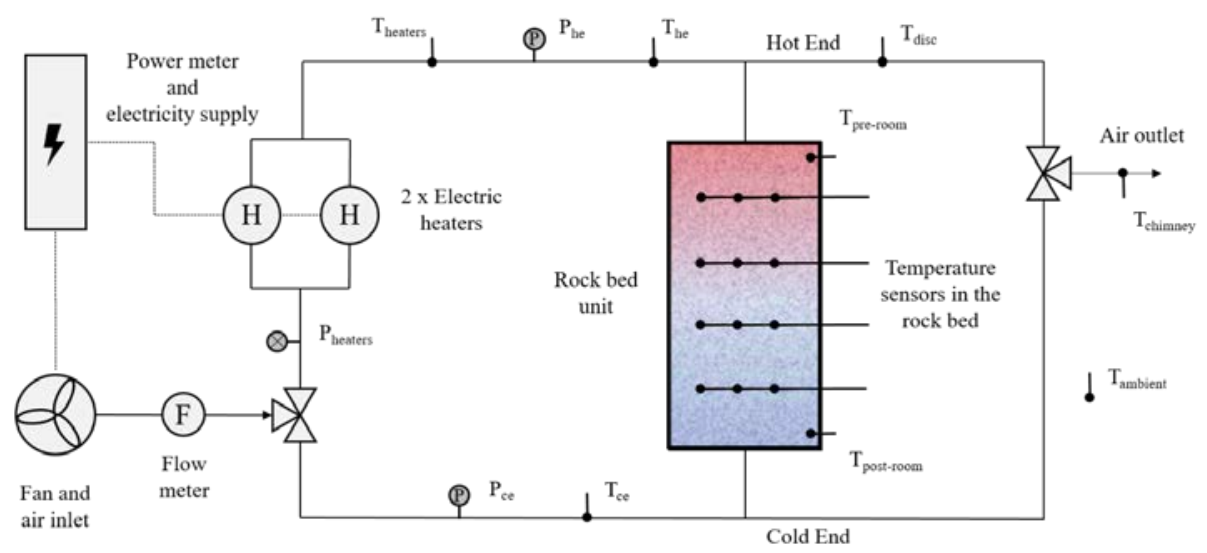

Figure 3. Schematic of the experimental setup showing data acquisition system (thermocouples, pressure gages, flow meter, energy meter), storage unit and air flow path. 
Table 4. Data acquisition system description.

\begin{tabular}{|c|c|c|c|c|}
\hline Component & No. & Description & Manufacturer & Model No. \\
\hline Fan & 1 & $\begin{array}{l}\text { Centrifugal fan: max flow rate } 325 \\
\mathrm{~m}^{3} / \mathrm{h} \text {, max pressure drop } 30000 \mathrm{~Pa}\end{array}$ & Becker & SV $300 / 1$ \\
\hline Heaters & 2 & $\begin{array}{l}15 \mathrm{~kW} \text { electric heaters working in } \\
\text { parallel }\end{array}$ & Leister & LE $10000 \mathrm{HT}$ \\
\hline Flow meter & 1 & $\begin{array}{l}\text { Turbine flow meter: range } 15-200 \\
\mathrm{~m} 3 / \mathrm{h}, 1.5 \% \text { O.R. accuracy }\end{array}$ & Bell & GFT-A-100-S(X)-S-S-N \\
\hline $\begin{array}{l}\text { Pressure } \\
\text { gages }\end{array}$ & 3 & $\begin{array}{l}\text { Low pressure transducers: } 2 \times 4000 \mathrm{~Pa} \\
\text { and } 1 \times 6000 \mathrm{~Pa}, 0.50 \% \text { F.S.O. }\end{array}$ & DMP & 343 \\
\hline $\begin{array}{l}\text { Temperature } \\
\text { sensors }\end{array}$ & 37 & $\begin{array}{l}\text { Type } \mathrm{K} \text { class } 1 \text { thermocouples with } \\
\text { stainless steel shielding, uncertainty } \\
\pm 1.5^{\circ} \mathrm{C} \text { from }-40 \text { to }+375^{\circ} \mathrm{C} \text { and } \\
\pm 0.004^{*} \Theta \text { from } 375 \text { to } 1000^{\circ} \mathrm{C}\end{array}$ & RS & $787-7863$ \\
\hline Energy meter & 1 & $\begin{array}{l}\text { Rated voltage } 230 \mathrm{~V} \pm 10 \% \text {, nominal } \\
\text { frequency } 50 \mathrm{~Hz} \pm 2 \% \text {, average } \\
\text { maximum permissible error }+0.1 \%\end{array}$ & Kamstrup & $382 \mathrm{M} \times 7$ \\
\hline DAQ & 1 & $\begin{array}{l}8 \text { channels for measuring flow and } \\
\text { pressures }\end{array}$ & $\begin{array}{l}\text { National } \\
\text { Instruments }\end{array}$ & NI $9203-4-20 m A$ \\
\hline DAQ & 1 & $\begin{array}{l}48 \text { channels to acquire signal from } \\
\text { thermocouples }\end{array}$ & $\begin{array}{l}\text { National } \\
\text { Instruments }\end{array}$ & $\mathrm{NI} 9213- \pm 78 \mathrm{mV}$ \\
\hline
\end{tabular}




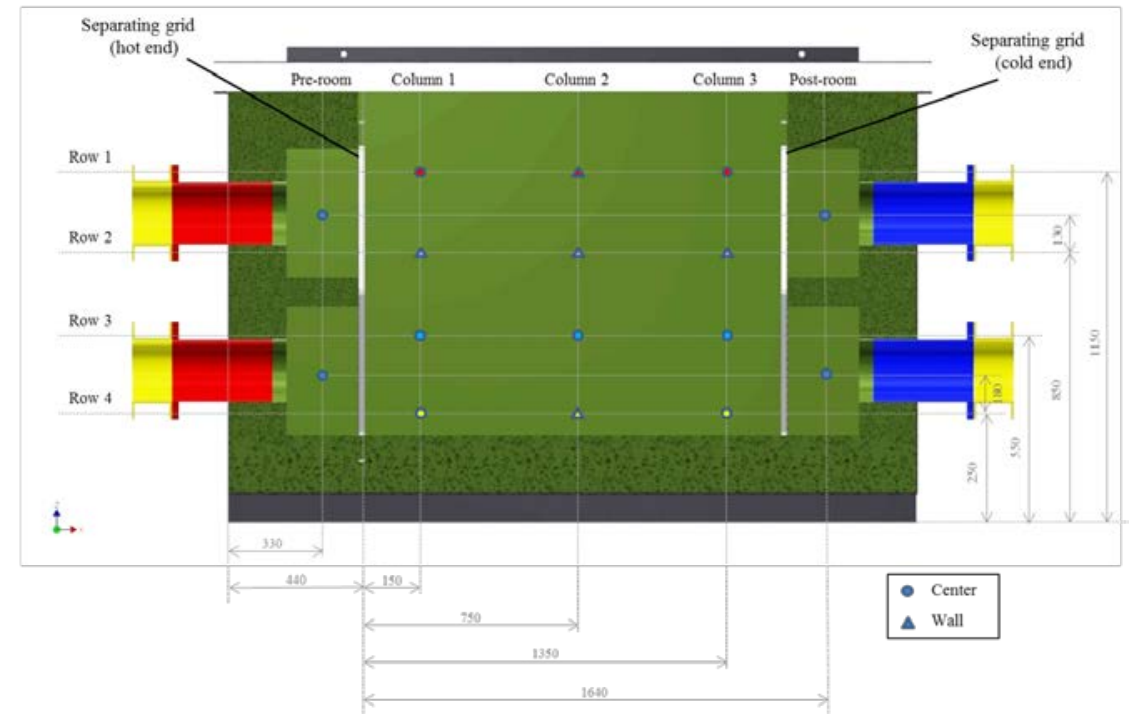

Figure 4. Section of the rock bed showing thermocouple locations inside. Measures in $\mathrm{mm}$.

Operating parameters used in the test are reported in Table 5. When calculating dimensionless parameters, it is important to note that there can be large temperature gradients in the bed and the average bed temperature is constantly increasing during the modelled charge cycle. Because temperature-dependent material properties are used, the precise dimensionless parameters will be a function of bed location and time. However, in this work the dimensionless parameters are used as a reference to reflect the general system operation. We have therefore evaluated dimensionless parameters at the inlet temperature to the bed and the reported values are given as reference values, except for the Richardson number, which is evaluated at the average between the starting rock temperature and the inlet temperature. In order to obtain a better agreement with experimental results, both in terms of temperature distribution and pressure drop in the porous medium, the value of permeability $K$ was slightly modified from the original value provided by the Carman-Kozeny equation $\left(1.51 \mathrm{E}-06 \mathrm{~m}^{2}\right)$.

Results of the comparison between experiments and model are presented both in terms of pressure and temperature. As far as pressure is concerned, the comparison between model and experiments was performed in the inlet pipe, at a distance of $1.5 \mathrm{~m}$ upstream of the rock bed. Results are reported in Figure 5. In order to reduce the instability of the experimental curve due to turbulence inside the pipe, each experimental value was averaged on the 500 points before and after it. Model results, instead, were averaged, based on the air flow distribution, on the line orthogonal to the air flow in the inlet pipe, in order to obtain one value for each time instant. In this figure, even though some instability is still present on the experimental curve, the trend suggests an average difference between the two curves around \pm 6 $\mathrm{Pa}$, with some peaks of $\pm 10 \mathrm{~Pa}$. Temperature comparisons are shown in Figure 6 . Both two-dimensional temperature profiles and single experimental temperature probe values compared with the 1D curves generated by the model are presented. Regarding the $2 \mathrm{D}$ temperature profiles, a tool based on a 1D 
porous media model, reported in [47] and [53], was used for the interpolation of temperature values resulting from experiments. Extrapolation outside the domain delimited by thermocouples is not considered in the present comparison. When comparing individual temperature probe measurements to model results, the curves represent a $1 \mathrm{D}$ evaluation of the $2 \mathrm{D}$ model results on the rows of thermocouples shown in Figure 4, at an average temperature between air and rocks. Experimental temperature values, instead, are represented by stars with error bars indicating the measurement uncertainty.

Regarding the model validation, some aspects need to be highlighted. First, the uncertainty on the real location inside the rock bed of the thermocouple on the vertical axis $( \pm 5 \mathrm{~cm})$ is accounted for by means of additional dashed lines; in this way the evaluation of the model is considered in the supposed location of the row of thermocouples, $5 \mathrm{~cm}$ above and $5 \mathrm{~cm}$ below it, generating therefore three 1D curves to compare with experimental values. Second, the uncertainty on the position of the thermocouple on the horizontal axis $( \pm 5 \mathrm{~cm})$ is described by horizontal error bars on the experimental points. Last, the uncertainty on the temperature measurement performed by the thermocouple $\left( \pm 1.5^{\circ} \mathrm{C}\right)$ is highlighted with vertical error bars on the experimental points. As it can be seen from Figure 4, thermocouples lying on Column 2 on the top and bottom layers of thermocouples are close to the container's walls. For this reason, they are influenced by the two major phenomena occurring in proximity of walls, i.e. flow channeling and heat losses through the wall. The first one is, basically, the higher fluid velocity close to a boundary in a porous media, due to increased permeability in that region. This entails, mainly, a quicker temperature increase in the initial transient of the charge phase. However, this effect was reduced in the experimental setup by adding a soft insulation layer on the internal surface of the container's walls. The second one causes a lower temperature in that region of the rock bed at steady state, given the heat exchange with the surrounding environment. In any case, in Figure $6 \mathrm{c}$ and $\mathrm{d}$ also these thermocouples are considered. Additional figures can be found in the Supplementary material.

Table 5. Operating parameters for the experimental validation.

\begin{tabular}{cccc} 
Parameter & Name & Value & Unit \\
\hline$\dot{V}$ & Normal volume flow rate & 75 & $\mathrm{~m}^{3} / \mathrm{h}$ \\
\hline$D_{p}$ & Particle diameter & 30 & $\mathrm{~mm}$ \\
\hline$\varepsilon$ & Porosity & 0.45 & - \\
\hline$T_{0}$ & Ambient temperature & 15 & ${ }^{\circ} \mathrm{C}$ \\
\hline$K$ & Permeability & $4.25 \mathrm{E}-07$ & $\mathrm{~m}^{2}$ \\
\hline$v$ & Air velocity in the bed & 0.02 & $\mathrm{~m} / \mathrm{s}$
\end{tabular}




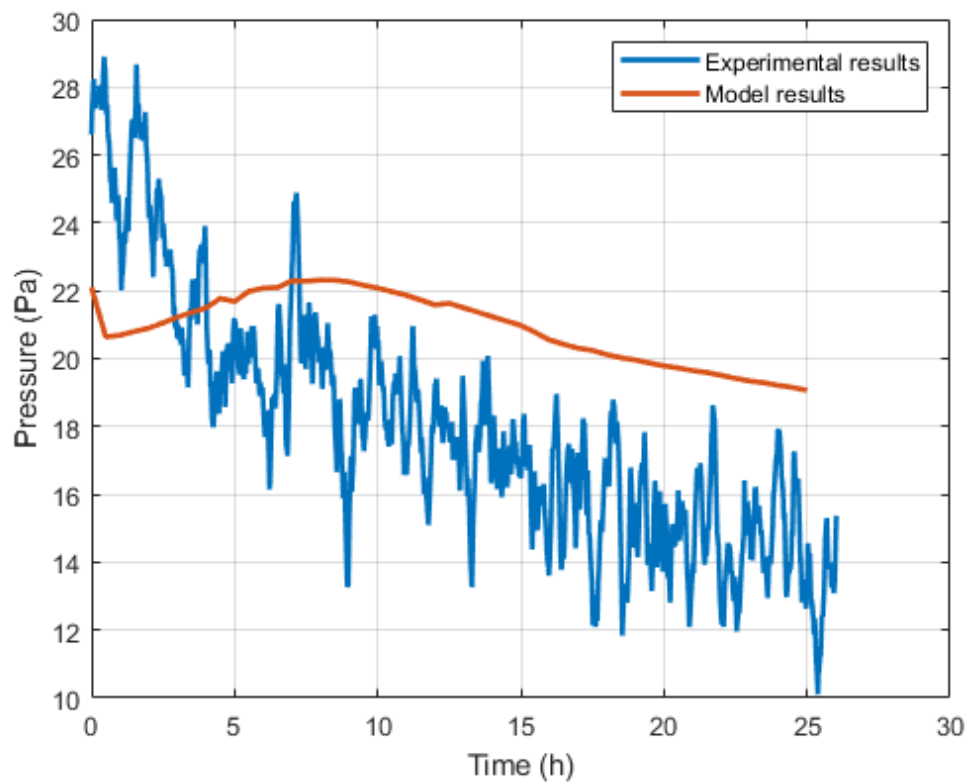

Figure 5. Pressure profile in the inlet pipe, $1.5 \mathrm{~m}$ upstream of the rock bed, experimental and model results. 


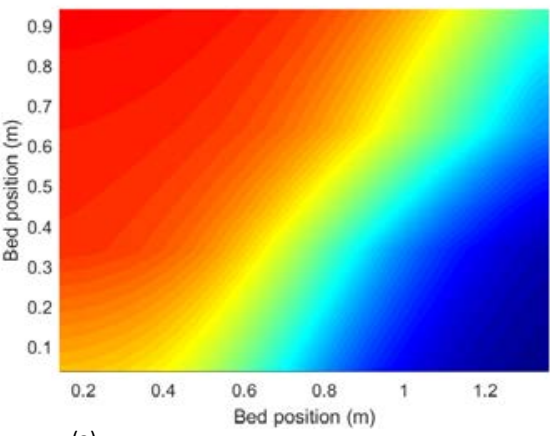

(a)

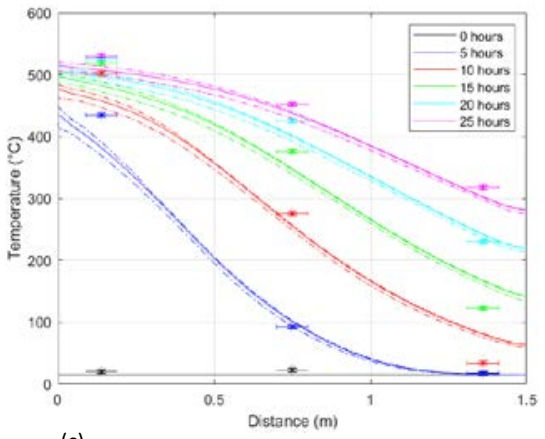

(c)

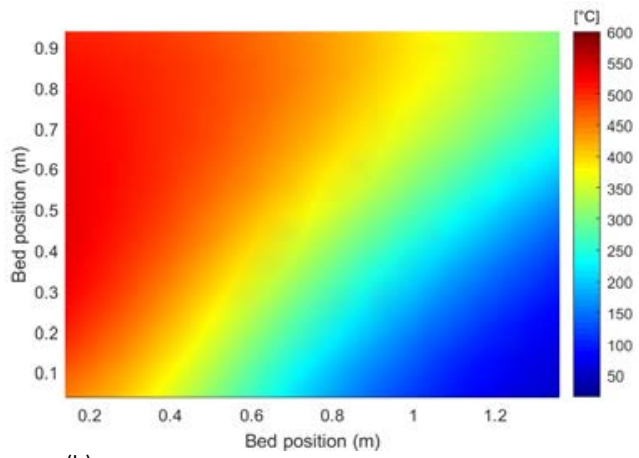

(b)

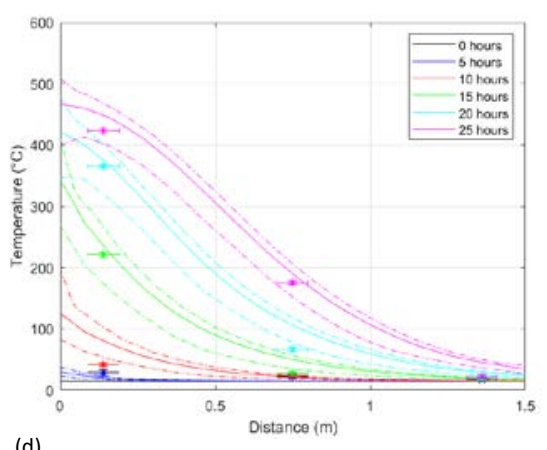

(d)

Figure 6. Comparison of model results with experimental data: two-dimensional temperature profile in the rock bed from experiments (a) and model (b), evaluation of the model corresponding to the top (c) and bottom (d) rows of thermocouples.

As it can be seen in Figure 6, there is acceptable agreement between model and test results. The foundational assumptions of the model, mainly the one of isotropic porous medium, and the inherent complexity in the estimation of the permeability, are the main aspects that prevent a better agreement. Also, the random packing direction of the stones entails some inner workings in the porous medium that cannot be described adequately by a porous media model. Random particle shape and surface roughness are also aspects that contribute to this. In addition to this, some channeling effects, i.e. higher air speed near the container walls due to higher permeability in that region, influence the temperature data logged by the wall thermocouples, compared to the ones in the middle of the porous medium. Comparing the energy stored in the rock bed at the end of the charge phase, the model predicts $275.18 \mathrm{kWh}$ stored in the rocks compared to the experimentally determined $241.65 \mathrm{kWh}$. This overestimation of approximately $12 \%$ given by the model can be explained, in addition to uncertainties stated above, by the degradation of the specific heat capacity of the rocks due to high temperature thermal cycling. As stated in [47], the average $\mathrm{Cp}$ of Swedish diabase is $1.13 \mathrm{~J} / \mathrm{g} \mathrm{K}$ for raw stones, whereas $0.96 \mathrm{~J} / \mathrm{g} \mathrm{K}$ for rocks that underwent thermal cycling at $800^{\circ} \mathrm{C}$. Given the inherent difficulty in estimating the regions of the rock bed in which 
stones suffered $\mathrm{Cp}$ degradation, raw rocks were used in the model. Therefore, a perfect agreement with a two dimensional model that aims at predicting the behavior of the core of the rock bed is quite hard to achieve. However, the model clearly captures the behavior of the rock bed during the charge phase. Given that the goal of the present paper is to investigate the influence of different parameters on the performance of the rock bed, rather than to provide highly accurate modeling of the thermal processes of the apparatus, this model validation is considered satisfactory.

\section{Results}

The presented model was used to investigate the influence of several parameters on the efficiency of the storage. Only charge cycles were simulated, starting from a bed in equilibrium with ambient conditions. The baseline model presents Swedish diabase as a storage material and the operating parameters shown in Table 6.

Table 6. Model inputs for the baseline HTTES unit working parameters.

\begin{tabular}{cccc} 
Parameter & Name & Value & Unit \\
\hline$\dot{V}$ & Normal volume flow rate & 275 & $\mathrm{Nm}^{3} / \mathrm{h}$ \\
\hline$D_{p}$ & Particle diameter & 20 & $\mathrm{~mm}$ \\
\hline$T_{0}$ & Ambient temperature & 15 & ${ }^{\circ} \mathrm{C}$ \\
\hline$K$ & Permeability & $6.69 \mathrm{E}-07$ & $\mathrm{~m}^{2}$ \\
\hline$t_{f}$ & Charge duration & 6 & $\mathrm{~h}$ \\
\hline$v$ & Air velocity in the bed & 0.076 & $\mathrm{~m} / \mathrm{s}$
\end{tabular}

Volume flow rate was chosen in order to satisfy a final state of charge of the bed equal to $80 \%$ in 6 hours by means of an air flow rate at $640^{\circ} \mathrm{C}$ that, considering heat losses along the inlet pipe, will provide a storage temperature of $600^{\circ} \mathrm{C}$. The state of charge is defined as the ratio between $E_{\text {stored }}$, the energy stored in the rock bed (Eq. 13), and the maximum heat capacity of the bed $C_{t h}$ (Eq. 14).

$$
\begin{gathered}
E_{\text {stored }}=\int_{V}(1-\varepsilon) \cdot \rho_{r} \cdot\left(u\left(T_{\text {amb }}\right)-u\left(T_{\text {storage }}\right)\right) d V \\
C_{t h}=(1-\varepsilon) \cdot V_{\text {storage }} \cdot \rho_{r} \cdot \int_{T_{a m b}}^{T_{\text {storage } m a x}} c_{r}(T) \cdot d T
\end{gathered}
$$

In these equations, $\varepsilon$ is the porosity of the rock bed, experimentally determined to be $0.45, \rho_{r}$ represents the density of the rocks measured as $3007 \mathrm{~kg} / \mathrm{m}^{3}, u$ is the internal energy of the rocks (Eq. 15), $v_{\text {storage }}$ is the volume of the storage $\left(1.5 \mathrm{~m}^{3}\right), c_{r}$ is the specific heat of the stones, $T_{\text {storage }}$ is the storage temperature, with a maximum of $600^{\circ} \mathrm{C}$ for this case, and $T_{a m b}$ is the ambient temperature, assumed $15^{\circ} \mathrm{C}$ for this work.

$$
u=\int_{T_{\text {ref }}}^{T_{\text {storage }}} c_{r}(T) d T
$$


Where $T_{r e f}$ is the reference temperature, at which $u$ is equal to zero. Assuming a charge efficiency $\eta_{C H}$ (Eq. 16) equal to 1 and a heat capacity of the rock bed $C_{t h}$ of $450 \mathrm{kWh}$, the air flow rate in normal conditions was found to be equal to the value reported in Table 6 .

$$
\eta_{C H}=\frac{E_{\text {stored }}}{E_{\text {heater }}+E_{\text {fan }}}
$$

Where $E_{H}$ and $E_{f a n}$ are respectively the electric energy input to the heater and to the fan, found as in Eq. 17 and Eq. 18.

$$
\begin{gathered}
E_{\text {heater }}=\int_{t_{0}}^{t_{\text {end }}} \dot{m}_{f} \cdot\left(h_{f}\left(T_{\text {heater }}\right)-h_{f}\left(T_{\text {amb }}\right)\right) d t \\
E_{\text {fan }}=\int_{t_{0}}^{t_{\text {end }}} \dot{m}_{f} \cdot v \cdot \Delta p d t
\end{gathered}
$$

Where $\dot{m}_{f}$ is the mass flow rate of air in the considered pipe, $h_{f}$ is the specific enthalpy of the air flow, $v$ is the specific volume of air, $\Delta p$ is the pressure drop across the rock bed, with a value around $10 \mathrm{~Pa}$ for the baseline test, and $t$ is time.

Permeability was calculated from the Carman-Kozeny equation (Eq. 2). The charge efficiency for the baseline test (Eq. 16), was found to be $87.14 \%$. Another parameter of interest in this analysis is the second principle charge efficiency $\eta_{I I, C H}$, calculated as in Eq. 19.

$$
\eta_{I, C H}=\frac{B_{\text {stored }}}{E_{\text {heater }}+E_{\text {fan }}}
$$

Here $B_{\text {stored }}$ represents the exergy stored in the rock bed and it is found as in Eq. 20.

$$
B_{\text {stored }}=\int_{V}(1-\varepsilon) \cdot \rho_{r} \cdot\left(b\left(T_{t_{0}}\right)-b\left(T_{t_{\text {end }}}\right)\right) d V
$$

Where $b$ is the specific exergy of rocks, calculated as:

$$
b=\int_{T_{\text {ref }}}^{T_{\text {storage }}} c_{r}(T) d T-T_{\text {ref }} \int_{T_{\text {ref }}}^{T_{\text {storage }}} c_{r}(T) \frac{d T}{T}
$$

\subsection{Parametric study}

\subsubsection{Particle size}

Several simulations were performed in order to assess the influence of particle diameter on the efficiency of the storage. Normal volume flow rate, ambient temperature and charge duration are the reported in Table 6. As shown in Figure 7, larger particles result in larger outlet losses, namely the amount of heat lost to the ambient in the form of warm air exiting the cold end of the rock bed when the storage medium has 
not been fully charged. This phenomenon is due to a larger permeability inside the porous medium that results from the use of larger stones. This entails a higher freedom of movement for the air inside the porous medium, hence cross-flow natural convective movements take place due to buoyancy phenomena, i.e. rising of air at high temperature $\left(600^{\circ} \mathrm{C}\right.$ in this case) due to its lower density. In particular, as the rock bed is progressively heated by hot air flow entering from the inlet pipes, in the case with smaller stones, i.e. lower permeability, buoyancy phenomena are limited; for this reason a more vertically uniform thermal gradient is visible (Figure 7a), as well as evenly distributed air flow streamlines. On the other hand, in a scenario with larger rock particles, i.e. higher permeability, buoyancy phenomena tend to move the entering hot air to the upper part of the porous medium, as it is shown in Figure 7c. In addition to this, smaller rocks correspond to an enhanced heat exchange between air and rocks, mainly because of an increased specific surface area and a higher convection coefficient between air and rocks. As a matter of fact, NTU decreases as the rock size increases. In Figure 7 it can be clearly seen that the difference from 5 to $15 \mathrm{~mm}$ rocks is not so relevant in terms of outlet losses, whereas $40 \mathrm{~mm}$ rocks lead to a considerably larger energy portion lost from the outlet pipe, for reasons described above. Figure 8 shows the average temperature of the air flow exiting from the rock bed at a distance of $1 \mathrm{~m}$ from the porous medium in the outlet pipe.

(a)

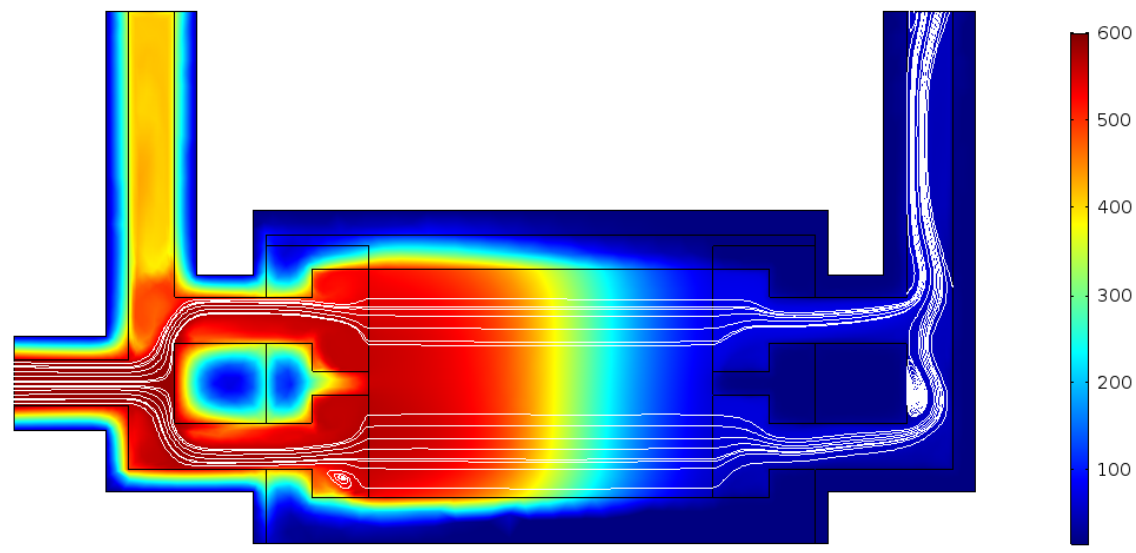



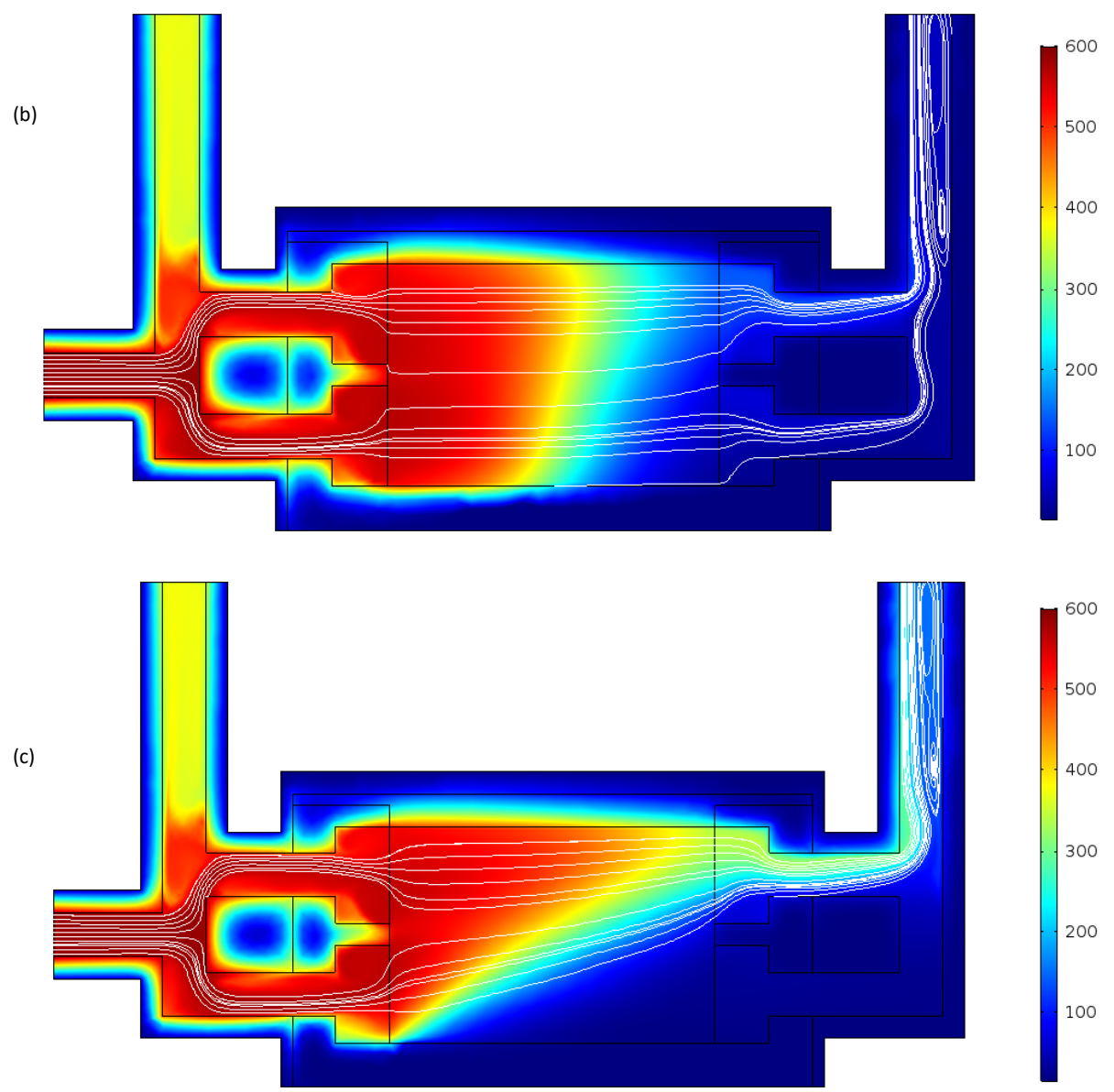

Figure 7. Temperature distribution and air flow streamlines after 6 hours of charge for rock sizes of $5 \mathrm{~mm}(\mathrm{a}), 15 \mathrm{~mm}$ (b) and 40 $\mathrm{mm}$ (c). The Reynolds number for these simulations is approximately 4, 12 and 32 respectively. NTU is $112.5,56.1$ and 32.6 . Temperature in ${ }^{\circ} \mathrm{C}$. 


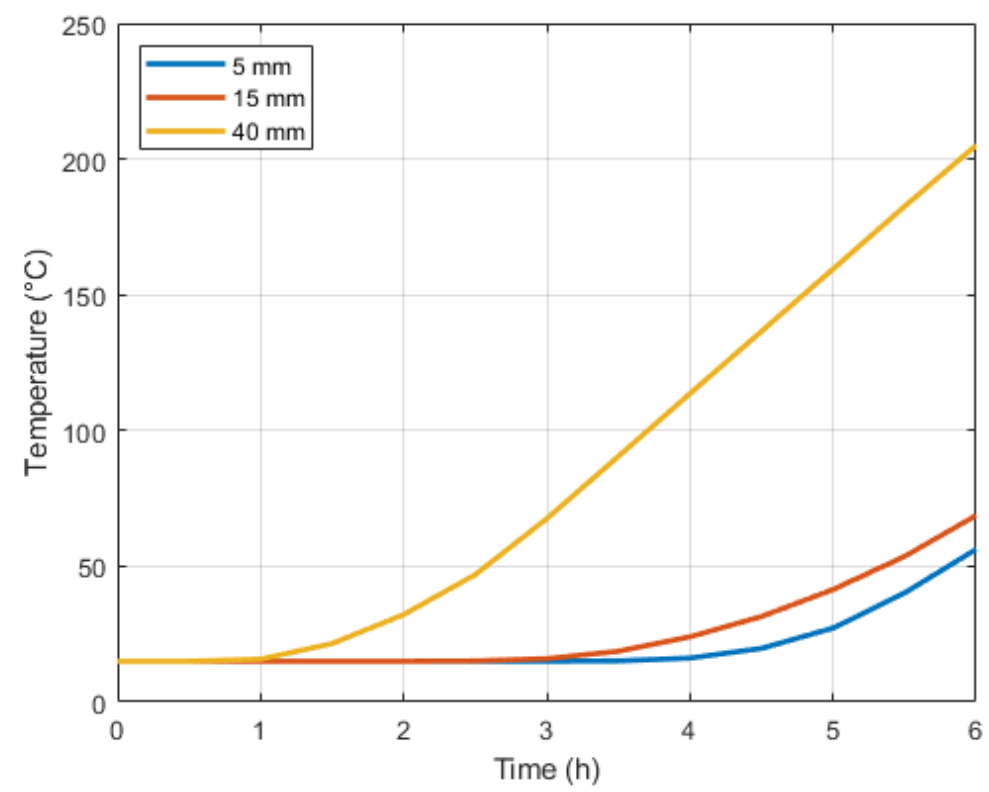

Figure 8. Outlet temperature as a function of time for simulations with $5 \mathrm{~mm}, 15 \mathrm{~mm}$ and $40 \mathrm{~mm}$ rock size.

The impact of rock size on the storage efficiency and important loss mechanisms were studied and presented in Figure 9. Outlet losses occur when temperature distributions in the vertical direction form and hot air exits the bed from the higher sections of the rock bed before the lower sections are fully charged. Wall losses are heat losses through the insulation and then either to ambient or the ground. Storage in insulation is heat stored in the insulation layers that cannot be recovered as quickly or efficiently as heat stored directly in the rocks. Figure 9 shows model results for these major loss mechanisms for a range of rock sizes. Wall losses are nearly constant for all rocks sizes while outlet losses dominate for larger rock sizes. For rock sizes lower than $20 \mathrm{~mm}$, there is only an incremental improvement in storage efficiency as the rock size decreases, as the permeability is already low enough to prevent the above-described phenomenon. On the other hand, lower rock sizes result in larger power required by the fan (Eq. 21) because of reduced permeability, hence larger pressure drop through the rock bed.

$$
P_{\text {fan }}=\dot{m} v \Delta p
$$

Where $\dot{m}$ is the air mass flow rate, $v$ is its specific volume and $\Delta p$ the pressure drop that the fan should satisfy. For the current model, the fan power's influence on the overall energy balance was small. As a matter of fact, the pressure drop through the porous medium for the smallest stones considered $(3 \mathrm{~mm}$ size) was approximately $513 \mathrm{~Pa}$, that considering an air flow rate of $275 \mathrm{Nm}^{3} / \mathrm{h}$ requires a $P_{\text {fan }}$ around $32.6 \mathrm{~W}$. However, this is an aspect to take into consideration carefully when dealing with industrial-scale systems. As a further comment, wall losses steadily account for $\sim 4 \%$ of the supplied energy for all the rock sizes, whereas storage in the insulation layers slightly decrease while moving towards larger rocks. This is 
mainly due to the higher permeability, which allows the air flow not to be stagnant in the hot end of the rock bed but to flow easily to the outlet.

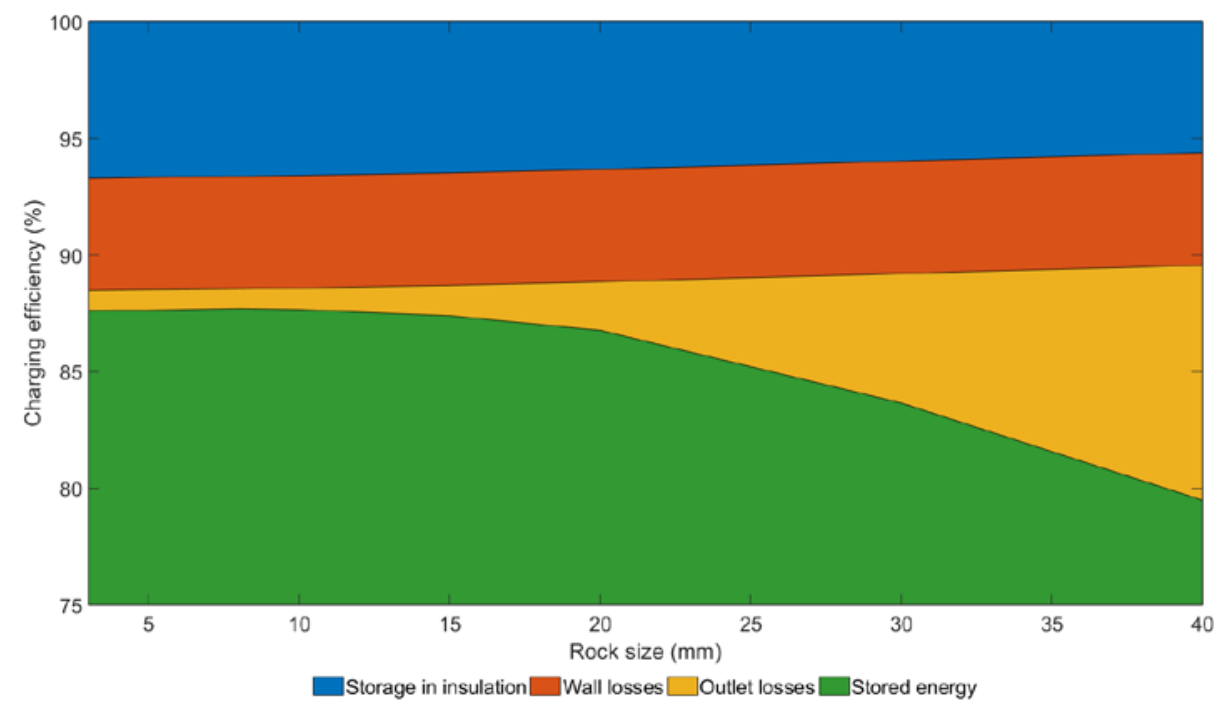

Figure 9. Charging efficiency and loss mechanism summary for different rock sizes.

\subsubsection{Air flow rate}

A comparison of different charging air flow rates was carried out in order to investigate its impact on the charge efficiency. In order to have comparable results, different charge durations were set for different air flow rates. The parameter that was kept equal, throughout the comparison, is the utilization constant $\mathrm{U}$ (Eq. 6). Considering a mass of rocks equal to $2495 \mathrm{~kg}$, as in the experimental setup, and a baseline simulation with a flow rate of $275 \mathrm{Nm}^{3} / \mathrm{h}$ and a duration of $6 \mathrm{~h}$, the comparison simulations were performed with $137 \mathrm{Nm}^{3} / \mathrm{h}$ for $12 \mathrm{~h}$ and $75 \mathrm{Nm}^{3} / \mathrm{h}$ for $22 \mathrm{~h}$, always with a particle size of $20 \mathrm{~mm}$. Temperature profiles are shown in Figure 10, and a summary of the results is given in Table 7. 


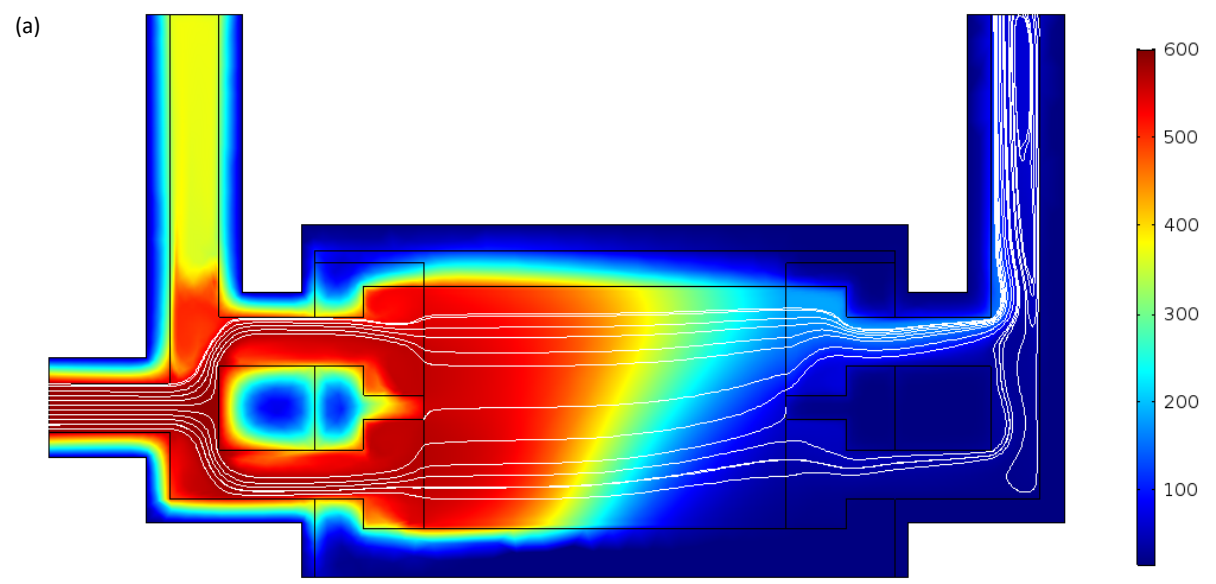


(b)

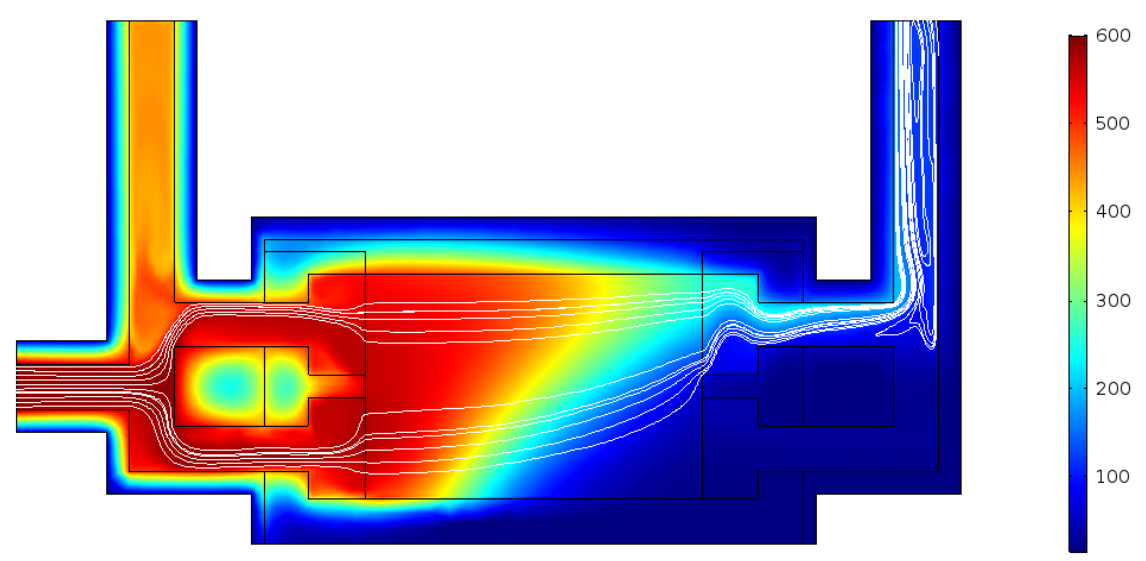

(c)

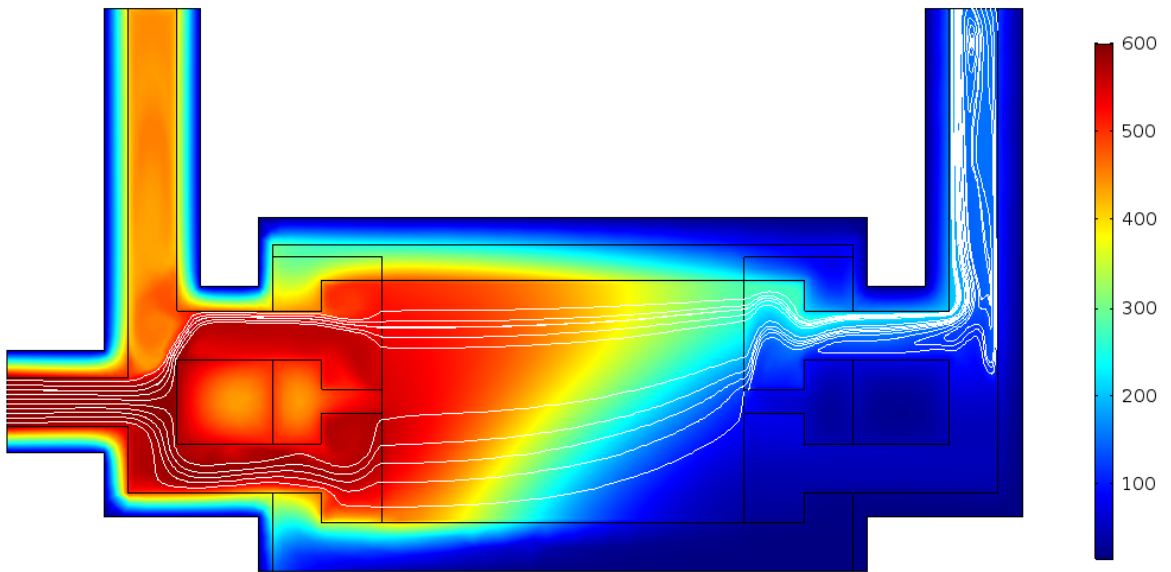

Figure 10. Temperature distribution and air flow rate of $275 \mathrm{Nm}^{3} / \mathrm{h}(a), 137 \mathrm{Nm}^{3} / \mathrm{h}(b)$ and $75 \mathrm{Nm}^{3} / \mathrm{h}$ (c) tests charged to a final utilization of 0.67 . Reynolds numbers for the three cases, in the order: 16,8 and 4 .Temperature in ${ }^{\circ} \mathrm{C}$.

Table 7. Summary of results of simulations at different air flow rates shown in Figure 10.

\begin{tabular}{cccccccc}
$\begin{array}{c}\text { Air flow } \\
\text { rate } \\
\left.\mathbf{( N m}^{\mathbf{3}} / \mathbf{h}\right)\end{array}$ & $\begin{array}{c}\text { Stored } \\
\text { energy } \\
\mathbf{( \% )}\end{array}$ & $\begin{array}{c}\text { Outlet } \\
\text { losses } \\
\mathbf{( \% )}\end{array}$ & $\begin{array}{c}\text { Wall } \\
\text { losses } \\
\mathbf{( \% )}\end{array}$ & $\begin{array}{c}\text { Storage in } \\
\text { insulation } \\
\mathbf{( \% )}\end{array}$ & $\begin{array}{c}\text { Relative } \\
\text { error } \\
\mathbf{( \% )}\end{array}$ & NTU & $\begin{array}{c}\text { Richardson } \\
\text { number }\end{array}$ \\
\hline 275 & 87.14 & 2.08 & 4.82 & 6.32 & 2.88 & 47.5 & $7.1 \mathrm{E}-2$ \\
\hline 137 & 78.25 & 5.12 & 9.61 & 7.77 & 3.44 & 95.3 & $2.9 \mathrm{E}-1$ \\
\hline 75 & 69.01 & 7.49 & 17.58 & 8.45 & 2.53 & 174.1 & $9.5 \mathrm{E}-1$
\end{tabular}


As it can be seen in Table 7, the largest air flow rate results in the highest charge efficiency, which has been verified experimentally [47]. It should be noted that since each simulation ends at the same utilization, the charge duration decreases with increasing flow rate. The increase in charge efficiency with increasing flow rate is likely due to two factors. The first is reduced buoyancy effects, as a fluid flow at higher speed results in lower Richardson numbers. This is due to the higher ratio of the forced convection in the flow direction to the free convection in the cross-flow direction. Therefore, larger air flow rates result in a more uniform and vertical heat front compared to lower flow rates, as shown by the streamlines in Figure 10. As a consequence, lower outlet losses take place for larger air flow rates. Second, the longer charge durations for the lower flow rates result in longer time periods for losses, such as conduction losses to ambient and axial conduction losses in the rock bed.

In addition to this, it is important to point out that the heat exchange between air flow and rocks in the presence of a faster fluid flow is less effective, as shown by the reduced NTU values. Specifically, the numerator $h_{\text {conv }}$ increases for higher flow rates $\left(13.4 \mathrm{~W} / \mathrm{m}^{2} \mathrm{~K}\right.$ for an air flow rate of $75 \mathrm{~m}^{3} / \mathrm{h}, 16.6 \mathrm{~W} / \mathrm{m}^{2} \mathrm{~K}$ for $137 \mathrm{~m}^{3} / \mathrm{h}$ and 22 for $275 \mathrm{~m}^{3} / \mathrm{h}$ ), because of the increase of Nu with fluid velocity. However, the increase in heat transfer coefficient is less than the increase of heat capacity associated with the air flow. For this reason, the increase of the air flow rate at the denominator causes a reduction of NTU for larger flow rates. The overall result is that the reduced buoyancy effects and loss mechanisms overcome the effects of lower NTU values and result in an overall improvement in charge efficiency.

\subsubsection{Rock material}

An investigation of different storage materials was performed in order to study the effect of different thermophysical properties of the storage medium on the charge efficiency. The considered materials are Swedish diabase and magnetite. Considering the operating parameters of the baseline model (Table 6), results are summarized in Table 8. The different temperature distributions generated for the two simulations are shown in Figure 11.

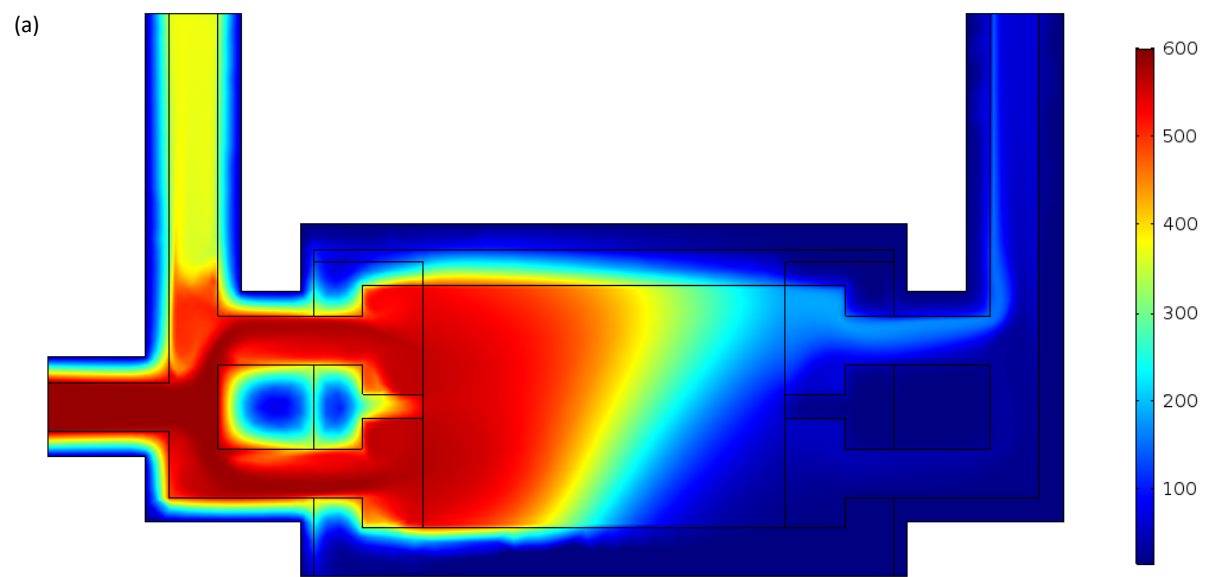




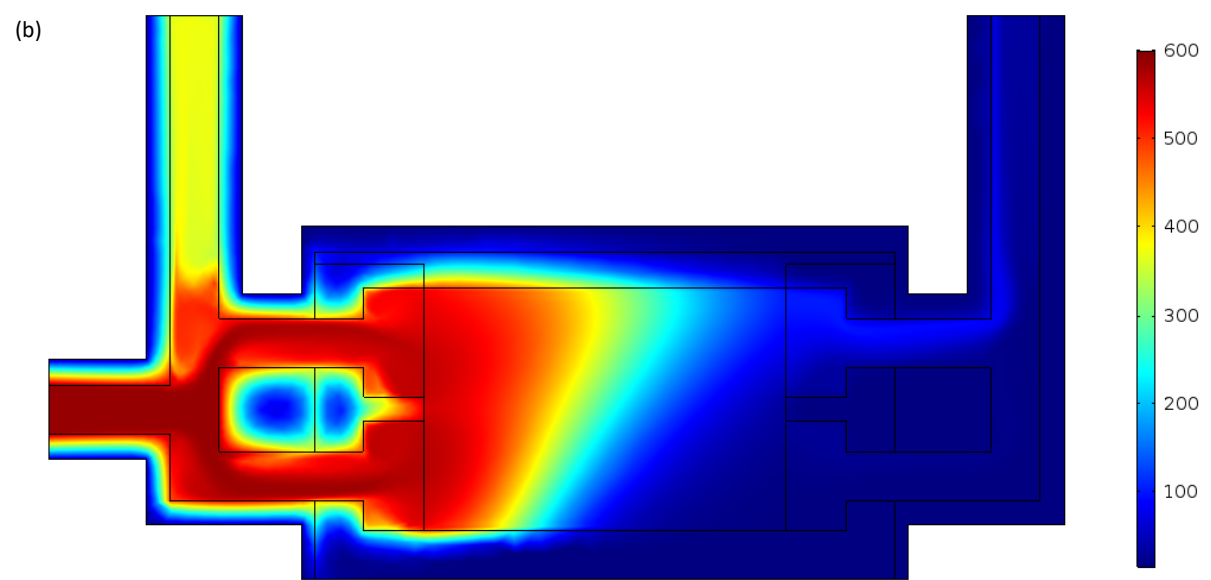

Figure 11. Temperature distribution after a $6 \mathrm{~h}$ charge with an air flow of $275 \mathrm{~m}^{3} / \mathrm{h}$ for diabase (a) and magnetite (b). The Reynolds number was 16 for both cases. $U$ was respectively equal to 0.67 and 0.39 . Temperature in ${ }^{\circ} \mathrm{C}$.

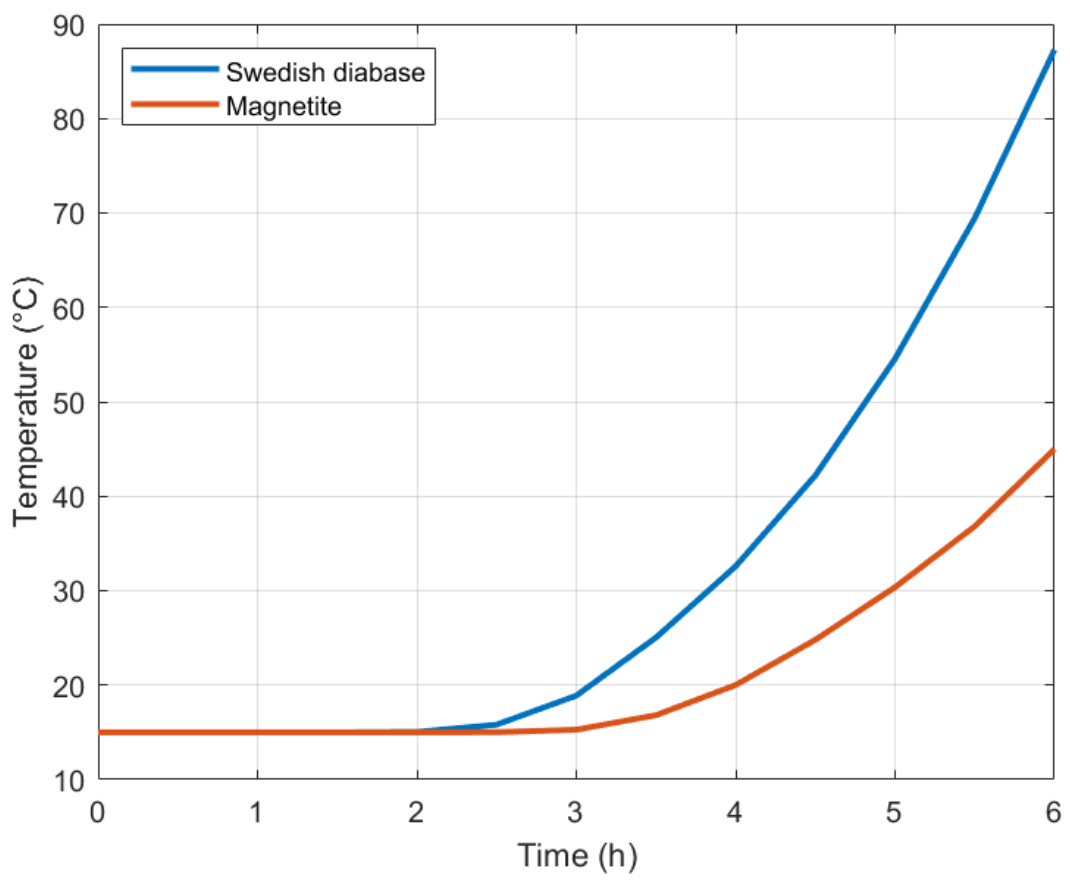

Figure 12. Outlet temperature evolution in time for a rock bed filled with Swedish diabase and magnetite. 
Table 8. Results of the simulations for diabase and magnetite.

\begin{tabular}{ccccccc} 
Rock type & $\begin{array}{c}\text { Stored } \\
\text { energy } \\
\text { (\%) }\end{array}$ & $\begin{array}{c}\text { 2nd } \\
\text { principle } \\
\text { efficiency } \\
\text { (\%) }\end{array}$ & $\begin{array}{c}\text { Outlet } \\
\text { losses } \\
\text { (\%) }\end{array}$ & $\begin{array}{c}\text { Wall losses } \\
\text { (\%) }\end{array}$ & $\begin{array}{c}\text { Storage in } \\
\text { insulation } \\
\text { (\%) }\end{array}$ & $\begin{array}{c}\text { Relative } \\
\text { error (\%) }\end{array}$ \\
\hline $\begin{array}{c}\text { Swedish } \\
\text { diabase }\end{array}$ & 89.65 & 34.29 & 2.08 & 4.82 & 6.32 & 2.88 \\
\hline Magnetite & 93.33 & 37.63 & 0.60 & 4.82 & 5.79 & 4.53
\end{tabular}

As it can be seen in Table 8, considering the same amount of provided energy, magnetite results in a more concentrated heat distribution, due to its larger storage density. This is quantified by a lower utilization value for the magnetite case. As a first effect, this results in reduced outlet losses. As shown in Figure 12, the outlet temperature for the magnetite case starts increasing later than for the Swedish diabase, and with a less steep behavior. In addition to this, rocks in the hot region reach a higher temperature and a more precise separation of the hot front is present in comparison with the diabase rock bed. This entails heat stored in a lower volume and, mostly, in heat stored at higher temperature. This means both larger energy and exergy are stored, hence higher values of first and second principle efficiencies for the magnetite in comparison with the Swedish diabase. In large scale plants, the useful effect of magnetite can be exploited with the goal of reducing the size of the storage unit, therefore reducing investment costs, despite a higher cost of the storage material itself.

\subsubsection{Insulation material}

From the analysis of the various simulations performed, it is clear that a considerable fraction of heat is stored in the insulation layers. Their relative importance in a small-scale system like the one described here is around $20 \%$ in terms of heat capacity. For this reason, different insulation layers were also considered in the simulations, in order to understand if by reducing the heat capacity of the insulation material, a larger fraction of heat could be stored in the rock bed. First, the baseline unit was compared with the same setup but insulated with insulation that has no thermal mass but with thermal conductivity equal to the baseline case; then, a system with ideal vacuum panels with both specific heat capacity and thermal conductivity of the insulation layers equal to zero was modeled. Operating parameters for the simulation are reported in Table 6. Results are given in Table 9.

Table 9. Results for different insulation materials.

\begin{tabular}{cccccc}
$\begin{array}{c}\text { Insulation } \\
\text { type }\end{array}$ & $\begin{array}{c}\text { Stored energy } \\
\text { (\%) }\end{array}$ & $\begin{array}{c}\text { Outlet losses } \\
\text { (\%) }\end{array}$ & $\begin{array}{c}\text { Wall losses } \\
\text { (\%) }\end{array}$ & $\begin{array}{c}\text { Storage in } \\
\text { insulation (\%) }\end{array}$ & $\begin{array}{c}\text { Relative } \\
\text { error (\%) }\end{array}$ \\
\hline Standard & 89.66 & 2.08 & 4.82 & 6.32 & 2.88 \\
\hline $\begin{array}{c}\text { No thermal } \\
\text { capacity }\end{array}$ & 95.03 & 2.21 & 4.82 & 0 & 2.06 \\
\hline $\begin{array}{c}\text { Vacuum } \\
\text { panels }\end{array}$ & 96.64 & 2.24 & 0 & 0 & -1.12 \\
\hline
\end{tabular}


The elimination of the heat capacity of the insulation layers leads to an increase in terms of charging efficiency of more than $5 \%$. The further elimination of wall losses has a less relevant impact on the results. The higher quantity of heat delivered to the rocks results in a slightly higher value of outlet losses, for the tests different from the baseline one. For these reasons, it becomes clear that the influence of the insulation is a key parameter in HTTES, especially when dealing with pilot plants of small sizes. In industrial applications, its relative importance tends to be less relevant, and results will be closer to the "vacuum panels" case presented here. In fact, for a storage system with a heat capacity of $50 \mathrm{MWh}$, i.e. one hundred times the storage capacity of the pilot plant presented here, the relative importance of the insulation layers in terms of heat capacity on the whole system is approximately $2 \%$.

\section{Conclusions}

This work presented the implementation of a two-dimensional model of a horizontal flow rock bed for HTTES. Good agreement was found with experimental data logged from the corresponding testing unit. A parametric study was performed in order to understand the influence of different design aspects on the two-dimensional temperature distribution and charge efficiency of the storage unit.

As far as the rock size analysis is concerned, it was found that its reduction has its main contribution in providing a steeper temperature gradient in the rock bed reducing the outlet losses, the effect of buoyancy, and increasing the charge efficiency. Rock sizes around $15 \mathrm{~mm}$ achieve good performance. The further reduction of the rock dimensions has no meaningful effect in terms of efficiency, but it results in larger pressure drops across the porous medium, due to reduced permeability, and therefore in the need for higher pressure fans. This aspect may lead to relevant issues in the design of an industrial-scale plant.

Regarding the impact of the air flow rate on the charge efficiency, it was found that charge periods with a shorter duration and a larger air flow rate result in higher efficiency in comparison to smaller air flow rates that deliver the same energy amount over a longer time period. The main reason for this is reduced buoyancy effects and a shorter time period for parasitic losses within the bed and to ambient. The faster air flow provides higher stability to the flow against the effect of buoyancy forces, which tend to convey the hot air to the top of the bed and leave cold pockets in the bottom part.

Regarding the rock material effect on the storage, it was shown that a material with higher density and specific heat capacity (magnetite in this case, compared to Swedish diabase) gives a more concentrated heat distribution in the storage medium. This means that magnetite allows heat to be stored in a smaller volume and at a higher temperature, resulting not only in higher efficiency, but also in reduced storage size, with a consequently lower investment cost.

Finally, the influence of the insulation material on the efficiency of the HTTES was studied. It was shown that an increase of more than $5 \%$ in the charging efficiency arises when eliminating the thermal capacity of the insulation layers. The introduction of adiabatic boundaries surrounding the system while holding the heat capacity at zero results, instead, in a minor impact on the results. This highlights that the insulation layers used in the model provide adequate thermal insulation, but lead, as a main issue, to the storage of some heat that cannot be efficiently recovered in the insulation material itself. This aspect is more relevant in small-scale plants, where the heat capacity of the insulation layers is quite large in comparison to the whole system, whereas in industrial-scale storage units results should be closer to the 
"vacuum-panels scenario", due to the small contribution of the insulation material on the overall thermal capacity.

Future investigation may focus on the analysis of consecutive charge-discharge cycles, in order to understand the behavior of the unit in a real-life application. In addition to this, an analysis on an industrial-scale system can be performed in order to have an insight on the real potential of the upscaling of the system. Also, in an upscaled scenario, an economical evaluation of the optimum plant size that would justify the adoption of magnetite as a storage material can be of considerable interest.

\section{Acknowledgements}

The authors would like to thank the Danish Energy Technology Development and Demonstration Program (EUDP) for funding this project (Contract No. EUDP 64016-0027). The authors would also like to express gratitude to Allan Schrøder Pedersen, Mike Wichmann and Jens Borchsenius for their valuable contribution in this work.

\section{Nomenclature}

$\begin{array}{ll}a_{s} & \text { Specific surface area }(1 / \mathrm{m}) \\ b & \text { Specific exergy }(\mathrm{J} / \mathrm{kg}) \\ B & \text { Exergy }(\mathrm{J}) \\ B i & \text { Biot number } \\ c & \text { Specific heat capacity }(\mathrm{J} / \mathrm{kg} \mathrm{K}) \\ c_{p} & \text { Specific heat capacity at constant pressure }(\mathrm{J} / \mathrm{kg} \mathrm{K}) \\ C & \text { Heat capacity }(\mathrm{J} / \mathrm{K}) \\ D_{p} & \text { Particle diameter }(\mathrm{m}) \\ E & \text { Energy }(\mathrm{J}) \\ g & \text { Gravitational constant; } \mathrm{g}=9.81\left(\mathrm{~m} / \mathrm{s}^{2}\right) \\ G r & \text { Grashof number } \\ h & \text { Specific enthalpy }(\mathrm{J} / \mathrm{kg}) \\ h_{\text {conv }} & \text { Convective heat transfer coefficient }\left(\mathrm{W} / \mathrm{m}^{2} \mathrm{~K}\right) \\ H & \text { Rock bed height }(\mathrm{m}) \\ l & \text { Identity matrix } \\ k & \text { Thermal conductivity }(\mathrm{W} / \mathrm{m} \mathrm{K}) \\ K & \text { Permeability }\left(\mathrm{m}^{2}\right) \\ L & \text { Rock bed length in flow direction }(\mathrm{m}) \\ m & \text { Mass }(\mathrm{kg}) \\ \dot{m} & \text { Mass flow rate }(\mathrm{kg} / \mathrm{s}) \\ n & \text { Surface normal vector } \\ N u & \text { Nusselt number } \\ N T U & \text { Number of transfer units } \\ p & \text { Pressure }(\text { Pa) } \\ P & \text { Power }(\mathrm{W}) \\ q & \text { Heat flux per surface area }\left(\mathrm{W} / \mathrm{m}^{2}\right) \\ Q & \text { Heat flux (W) } \\ R_{p} & \text { Particle radius }(\mathrm{m}) \\ R e & \text { Reynolds number } \\ & \end{array}$




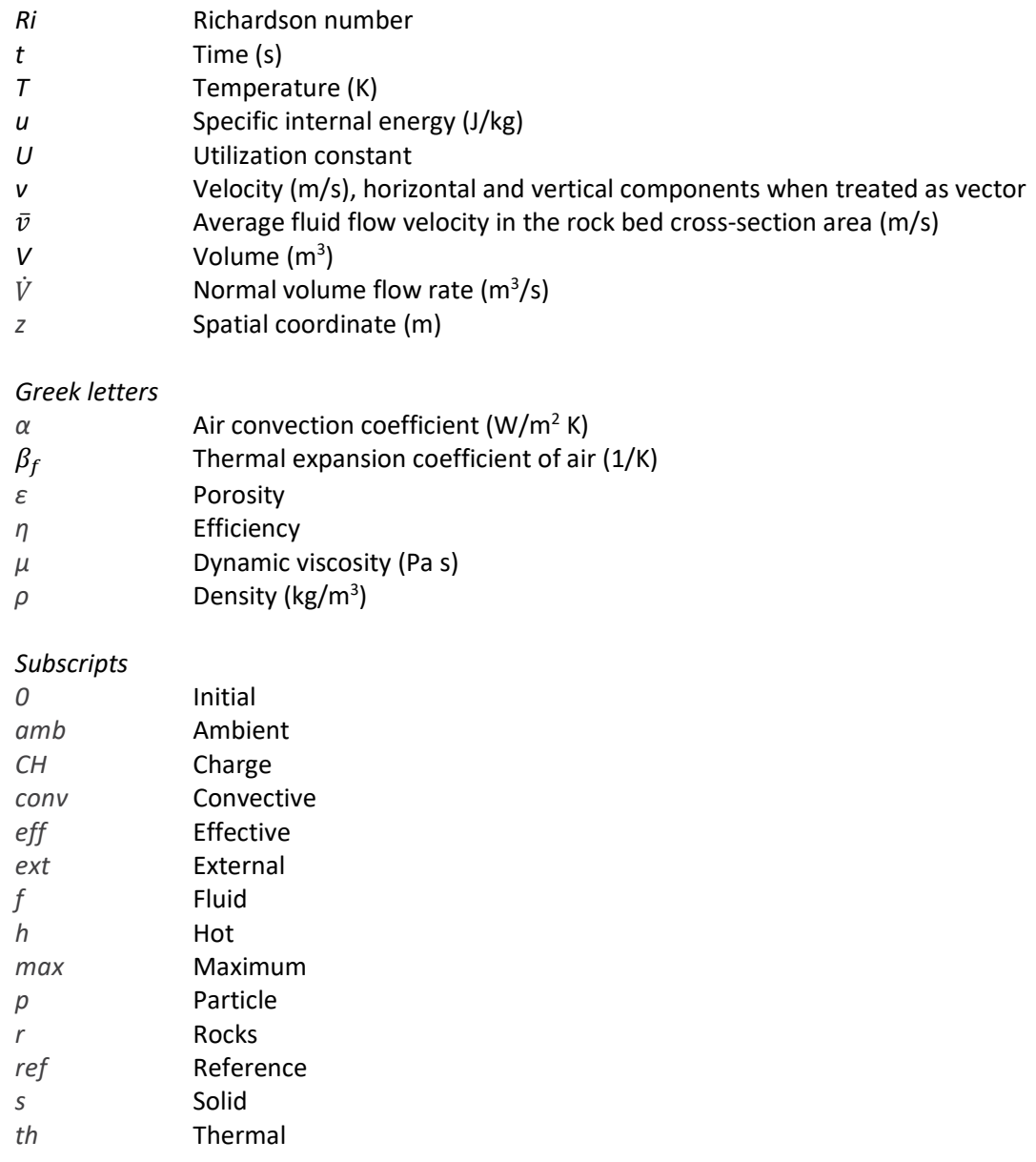

\section{References}

[1] P. Nørgård, L. Lohse, Vision for Smart Energy in Denmark, Technical University of Denmark, 2015.

[2] P.K. and H.A. R. Kempener, "SMART GRIDS," IRENA - International Renewable Energy Agency, (2013).

[3] C.K. Ekman, S.H. Jensen, Prospects for large scale electricity storage in Denmark, Energy Convers. Manag. 51 (2010) 1140-1147. doi:10.1016/j.enconman.2009.12.023.

[4] J. Eyer, G. Corey, Energy storage for the electricity grid: Benefits and market potential assessment guide, Sandia Natl. Lab. 20 (2010) 5. 
[5] B. Zakeri, S. Syri, Corrigendum to "Electrical energy storage systems: A comparative life cycle cost analysis" [Renew. Sustain. Energy Rev. 42 (2015) 569-596], Renew. Sustain. Energy Rev. 53 (2015) 1634-1635. doi:10.1016/j.rser.2015.09.095.

[6] X. Luo, J. Wang, M. Dooner, J. Clarke, Overview of current development in electrical energy storage technologies and the application potential in power system operation, Appl. Energy. 137 (2015) 511-536. doi:10.1016/j.apenergy.2014.09.081.

[7] H. Chen, T.N. Cong, W. Yang, C. Tan, Y. Li, Y. Ding, Progress in electrical energy storage system: A critical review, Prog. Nat. Sci. 19 (2009) 291-312. doi:10.1016/j.pnsc.2008.07.014.

[8] A.Z. Weber, M.M. Mench, J.P. Meyers, P.N. Ross, J.T. Gostick, Q. Liu, Redox flow batteries: A review, J. Appl. Electrochem. 41 (2011) 1137-1164. doi:10.1007/s10800-011-0348-2.

[9] R. Madlener, J. Latz, Economics of centralized and decentralized compressed air energy storage for enhanced grid integration of wind power, Appl. Energy. 101 (2013) 299-309. doi:10.1016/j.apenergy.2011.09.033.

[10] M.E. Amiryar, K.R. Pullen, A review of flywheel energy storage system technologies and their applications, Appl. Sci. 7 (2017). doi:10.3390/app7030286.

[11] D. MacKay, N. Winse, The future role for energy storage in the UK Main Report, 2011.

[12] Y. Luo, X. yu Wu, Y. Shi, A.F. Ghoniem, N. Cai, Exergy analysis of an integrated solid oxide electrolysis cell-methanation reactor for renewable energy storage, Appl. Energy. 215 (2018) 371-383. doi:10.1016/j.apenergy.2018.02.022.

[13] IEC, Executive summary, Bus. Strateg. Environ. 2 (2007) 1-3. doi:10.1002/bse.3280020501.

[14] A. Arabkoohsar, G.B. Andresen, Dynamic energy, exergy and market modeling of a High Temperature Heat and Power Storage System, Energy. 126 (2017) 430-443. doi:10.1016/j.energy.2017.03.065.

[15] H. Kerskes, F. Bertsch, B. Mette, A. Wörner, F. Schaube, Thermochemische Energiespeicher, Chemie-Ingenieur-Technik. 83 (2011) 2014-2026. doi:10.1002/cite.201100091.

[16] M.F. Demirbas, Thermal Energy Storage and Phase Change Materials: An Overview, Energy Sources, Part B Econ. Planning, Policy. 1 (2007) 85-95. doi:10.1080/009083190881481.

[17] S.M. Hasnain, Review on sustainable thermal energy storage technologies, Part I: heat storage materials and techniques, Energy Convers. Manag. 39 (1998) 1127-1138. doi:10.1016/S01968904(98)00025-9.

[18] S. Kuravi, J. Trahan, D.Y. Goswami, M.M. Rahman, E.K. Stefanakos, Thermal energy storage technologies and systems for concentrating solar power plants, Prog. Energy Combust. Sci. 39 (2013) 285-319. doi:10.1016/j.pecs.2013.02.001.

[19] L. Miró, J. Gasia, L.F. Cabeza, Thermal energy storage (TES) for industrial waste heat (IWH) recovery: A review, Appl. Energy. 179 (2016) 284-301. doi:10.1016/j.apenergy.2016.06.147.

[20] L.F. Cabeza, E. Oró, Thermal Energy Storage for Renewable Heating and Cooling Systems, 2015. doi:10.1016/B978-1-78242-213-6.00007-2.

[21] J.A. Duffie, W.A. Beckman, J. McGowan, Solar Engineering of Thermal Processes, John Wiley \& 
Sons, 1985. doi:10.1119/1.14178.

[22] G. Zanganeh, A. Pedretti, S. Zavattoni, M. Barbato, A. Steinfeld, Packed-bed thermal storage for concentrated solar power - Pilot-scale demonstration and industrial-scale design, Sol. Energy. 86 (2012) 3084-3098. doi:10.1016/j.solener.2012.07.019.

[23] J.B. Rosen, Kinetics of a Fixed Bed System for Solid Diffusion into Spherical Particles, J. Chem. Phys. 20 (1952) 387-394. doi:10.1063/1.1700431.

[24] A.S. Pedersen, K. Engelbrecht, S. Soprani, M. Wichmann, J. Borchsenius, F. Marongiu, K. Dinesen, T. Ulrich, L. Algren, K. Capion, O. Alm, L. Christensen, S.N. Rasmussen, High-Temperature Thermal Energy Storage for electrification and district heating, in: 2018.

[25] Shitzer, Levy, Transient behaviour of a rock-bed thermal storage system subjected to variable inlet air temperatures: analysis and experimentation, Trans. ASME. J. Sol. Energy Eng. 105 (1983) 200-206. doi:10.1115/1.3266366.

[26] S. Flueckiger, Z. Yang, S. V. Garimella, An integrated thermal and mechanical investigation of molten-salt thermocline energy storage, Appl. Energy. 88 (2011) 2098-2105. doi:10.1016/j.apenergy.2010.12.031.

[27] T.E.W. Schumann, Heat transfer: A liquid flowing through a porous prism, J. Franklin Inst. 208 (1929) 405-416. doi:10.1016/S0016-0032(29)91186-8.

[28] J.P. Coutier, E.A. Farber, Two applications of a numerical approach of heat transfer process within rock beds, Sol. Energy. 29 (1982) 451-462. doi:10.1016/0038-092X(82)90053-6.

[29] D.E. Beasley, J.A. Clark, Transient response of a packed bed for thermal energy storage, Int. J. Heat Mass Transf. 27 (1984) 1659-1669. doi:10.1016/0017-9310(84)90278-3.

[30] K.A.R. Ismail, R. Stuginsky Jr, A parametric study on possible fixed bed models for $\mathrm{pcm}$ and sensible heat storage, Appl. Therm. Eng. 19 (1999) 757-788. doi:10.1016/S1359-4311(98)000817.

[31] A. Andreozzi, B. Buonomo, O. Manca, P. Mesolella, S. Tamburrino, Numerical investigation on sensible thermal energy storage with porous media for high temperature solar systems, in: J. Phys. Conf. Ser., 2012: p. 12150. doi:10.1088/1742-6596/395/1/012150.

[32] R.J. Krane, A Second Law analysis of the optimum design and operation of thermal energy storage systems, Int. J. Heat Mass Transf. 30 (1987) 43-57. doi:10.1016/0017-9310(87)90059-7.

[33] M.J. Taylor, R.J. Krane, J.R. Parsons, Second Law Optimization of a Sensible Heat Thermal Energy Storage System With a Distributed Storage Element-Part II: Presentation and Interpretation of Results, J. Energy Resour. Technol. 113 (2008) 27. doi:10.1115/1.2905776.

[34] J.J.N. Gonzalez, J.G.C. de Gortari, E.T. Reyes, Exergy analysis of a rock bed thermal storage system, Int. J. Exergy. 5 (2007) 18. doi:10.1504/ijex.2008.016010.

[35] S. Ergun, Fluid flow through packed columns, Chem. Eng. Prog. 48 (1952) 89-94.

[36] K.G. Allen, T.W. von Backström, D.G. Kröger, Packed bed pressure drop dependence on particle shape, size distribution, packing arrangement and roughness, Powder Technol. 246 (2013) 590600. doi:10.1016/j.powtec.2013.06.022. 
[37] S.A. Zavattoni, M.C. Barbato, A. Pedretti, G. Zanganeh, CFD simulations of a pebble bed thermal energy storage system accounting for porosity variations effects, in: SolarPACES 2011 Conf. Pap. ID, 2011.

[38] K.G. Allen, T.W. Von Backström, D.G. Kröger, Packed rock bed thermal storage in power plants: Design considerations, Energy Procedia. 49 (2013) 666-675. doi:10.1016/j.egypro.2014.03.072.

[39] K.G. Allen, T.W. von Backström, D.G. Kröger, Rock bed pressure drop and heat transfer: Simple design correlations, Sol. Energy. 115 (2015) 525-536. doi:10.1016/j.solener.2015.02.029.

[40] C. Singh, R.G. Tathgir, K. Muralidhar, Energy storage in fluid saturated porous media subjected to oscillatory flow, Heat Mass Transf. Und Stoffuebertragung. 45 (2009) 427-441. doi:10.1007/s00231-008-0435-z.

[41] S.A. Zavattoni, M.C. Barbato, A. Pedretti, G. Zanganeh, A. Steinfeld, High temperature rock-bed TES system suitable for industrial-scale CSP plant - CFD analysis under charge / discharge cyclic conditions, 46 (2014) 124-133. doi:10.1016/j.egypro.2014.01.165.

[42] H. Agalit, N. Zari, M. Maalmi, M. Maaroufi, Numerical investigations of high temperature packed bed TES systems used in hybrid solar tower power plants, Sol. Energy. 122 (2015) 603-616. doi:10.1016/j.solener.2015.09.032.

[43] L. Geissbühler, M. Kolman, G. Zanganeh, A. Haselbacher, A. Steinfeld, Analysis of industrial-scale high-temperature combined sensible/latent thermal energy storage, Appl. Therm. Eng. 101 (2016) 657-668. doi:10.1016/j.applthermaleng.2015.12.031.

[44] M. Hänchen, S. Brückner, A. Steinfeld, High-temperature thermal storage using a packed bed of rocks - Heat transfer analysis and experimental validation, Appl. Therm. Eng. 31 (2011) 17981806. doi:10.1016/J.APPLTHERMALENG.2010.10.034.

[45] G. Zanganeh, A. Pedretti, A. Haselbacher, A. Steinfeld, Design of packed bed thermal energy storage systems for high-temperature industrial process heat, Appl. Energy. 137 (2015) 812-822. doi:10.1016/j.apenergy.2014.07.110.

[46] ASHRAE, ASHRAE Handbook of Fundamentals, 2009. doi:10.1039/c1cs15219j.

[47] S. Soprani, F. Marongiu, L. Christensen, O. Alm, K. Dinesen, K. Engelbrecht, Design and Testing of a Horizontal Rock Bed for High Temperature Thermal Energy Storage, Accept. Publ. Appl. Energy. (n.d.).

[48] F. Birch, H. Clark, The thermal conductivity of rocks and its dependence upon temperature and composition; Part II, Am. J. Sci. 238 (2010) 613-635. doi:10.2475/ajs.238.9.613.

[49] Y. Grosu, A. Faik, I. Ortega-Fernández, B. D’Aguanno, Natural Magnetite for thermal energy storage: Excellent thermophysical properties, reversible latent heat transition and controlled thermal conductivity, Sol. Energy Mater. Sol. Cells. 161 (2017) 170-176. doi:10.1016/j.solmat.2016.12.006.

[50] B.S. Baclic, G.D. Dragutinovic, Operation of counterflow regenerators, Computational Mechanics Publications, 1998.

[51] T.L. Bergman, F.P. Incropera, D.P. DeWitt, A.S. Lavine, Fundamentals of heat and mass transfer, John Wiley \& Sons, 2011. 
[52] N. Wakao, S. Kaguei, T. Funazkri, Effect of fluid dispersion coefficients on particle-to-fluid heat transfer coefficients in packed beds. Correlation of nusselt numbers, Chem. Eng. Sci. 34 (1979) 325-336. doi:10.1016/0009-2509(79)85064-2.

[53] K. Engelbrecht, C.R.H. Bahl, Evaluating the effect of magnetocaloric properties on magnetic refrigeration performance, J. Appl. Phys. 108 (2010) 123918. doi:10.1063/1.3525647. 